\title{
Description of two free-living nematode species of Halomonhystera disjuncta complex (Nematoda: Monhysterida) from two peculiar habitats in the sea
}

\author{
Alexei V. Tchesunov $\cdot$ Daria A. Portnova • \\ Jelle van Campenhout
}

Received: 29 May 2014/Revised: 26 September 2014/Accepted: 29 September 2014/Published online: 20 November 2014

(c) Springer-Verlag Berlin Heidelberg and AWI 2014

\begin{abstract}
Morphological descriptions of two Halomonhystera species (Nematoda, Monhysterida) are presented (Halomonhystera hermesi and Halomonhystera socialis). Halomonhystera hermesi sp. $\mathrm{n}$. occurs in a dense monospecific and homogeneous population on bacterial mats in the Håkon Mosby mud volcano in the Barents Sea at a depth of $1,280 \mathrm{~m}$. The species is an endemic lineage distinctly separated from other shallow-water cryptotaxa of the Halomonhystera disjucta species complex on the base of the mitochondrial gene cytochrome oxidase subunit I (genetic divergence $19.6-23.8 \%$ ) and nuclear genetic markers, and on the base of morphometrics by Van Campenhout et al. (2014). H. socialis (Bütschli 1874) is redescribed on the basis of White Sea specimens. This species dwells in mass on the detached kelp accumulation in the upper sublittoral. H. socialis is differentiated from other species of the Halomonhystera disjuncta complex
\end{abstract}

Communicated by H-D. Franke.

A. V. Tchesunov $(\bowtie)$

Department of Invertebrate Zoology, Faculty of Biology,

Moscow State University, Moscow 119991, Russia

e-mail: AVTchesunov@yandex.ru

D. A. Portnova

P.P. Shirshov's Institute of Oceanology, Russian Academy of Sciences, Nakhimovsky prosp., 36, Moscow 117851, Russia

J. van Campenhout

Research Group Marine Biology, Biology Department, Ghent

University, Krijgslaan 281-S8, 9000 Ghent, Belgium

J. van Campenhout

Center for Molecular Phylogenetics and Evolution (CeMoFe),

Ghent University, K.L. Ledeganckstraat 35, 9000 Ghent,

Belgium morphometrically by a larger body size and by genetic divergence in nuclear markers. The genus Halomonhystera Andrássy 2006 is redefined, and its morphospecies list is reviewed. Species H. bathislandica (Riemann 1995) comb. n., H. fisheri (Zekely et al. 2006) comb. n., H. islandica (De Coninck 1943) comb. n. and $H$. vandoverae (Zekely et al. 2006) comb. n. are transferred to Halomonhystera from Thalassomonhystera; H. paradisjuncta (de Coninck 1943) comb. n., H. rotundicapitata (Filipjev 1922) comb. n. and H. taurica (Tsalolikhin 2007) comb. n. transferred to Halomonhystera from Geomonhystera. Halomonhystera ambiguoides (Bütschli 1874) is considered as species inquirenda because of incompleteness of its diagnosis.

Keywords Cryptospecies - Deep-sea biodiversity · Freeliving nematodes - Halomonhystera $\cdot$ Monhysteridae .

Taxonomy

\section{Introduction}

Species of Halomonhystera Andrássy 2006 are mostly well distinguishable by position of the vulva shifted posteriad close to the anal opening. The type species $H$. disjuncta (Bastian 1865) is one of the most well-known marine nematodes. As a model species, $H$. disjuncta (then under generic names Monhystera and Geomonhystera) has been subject of previous studies on morphology and ultrastructure (Geraert et al. 1981; Van de Velde and Coomans 1987, 1989, 1991, 1992), demography, physiology and energetics (Chitwood and Murphy 1964; Vranken et al. 1988; Herman and Vranken 1988; Herman et al. 1984), impact of temperature and salinity on life cycle (Gerlach and Schrage 1971; Vranken and Heip 1986), and toxicology (Vranken et al. 1984, 1985, 1989). 
Data on geographical records of $H$. disjuncta and related species have been summarized by Gerlach and Riemann (1973), Jacobs (1987) and in some subsequent publications thereafter. The species occur very frequently along the coasts of the North Atlantic (e.g., North Sea, Baltic Sea, Norway Sea, English Channel, Nova Scotia, St. Lawrence), North Pacific (Japan, California to Washington) and Arctic (Iceland, Jan Mayen, Svalbard) seas of temperate and cold zones. Species of $H$. disjuncta complex have also been recorded in the South Atlantic (Fuegian Archipelago, Falkland Islands, South Georgia, Patagonia), South Pacific (Chile, Campbell Island) and South Indian Ocean (Kerguelen Archipelago) (records are summarized in Gerlach and Riemann 1973 and Jacobs 1987; see also following later publications below in References). Thus, mapped localities of $H$. disjuncta species complex are indicated on shelves in cool- and cold-water zones of both North Hemisphere and South Hemisphere. The species were not registered within the tropical belt except for one very brief mention on its occurrence in the Bay of Bengal. The species complex could not be considered as a true cosmopolitan but has a wide tropical gap in between two huge areas of cooler water. Yet, some Halomonhystera species have been found at low latitudes but are restricted to deepsea environments (e.g., in Angola Basin, SW Atlantic, depth about 5,500 $\mathrm{m}$, personal data of the first author).

Halomonhystera species are often found in mass, especially in sites enriched with dissolved and particulate organic matter, e.g., on living macrophytes (e.g., Kito 1982; Trotter and Webster 1983), in piles of detached dying and dead decaying macrophytes (e.g., Riemann 1968; Mokievsky et al. 2005) but also on live macroinvertebrates (e.g., on mouth parts and in the intestine of some decapod and mysidacean crustaceans-Steiner 1958; in body cavity of sandy beach amphipods-Poinar 2010, within body of a starfish-personal observation of the first author). While dwelling in biotopes with high organic contents, $H$. exgr disjuncta often is the most dominant or the single nematode species present. Like any other bacterivore species, $H$. disjuncta and related species depend on the density of bacteria in the environment. Vranken et al. (1988) showed that threshold concentration of bacteria allowing normal existence and development of $H$. disjuncta population is $10^{7}$ cells $/ \mathrm{ml}$; if bacterial cell densities are lower, nematodes in larger part do not reach puberty and show retard development at juvenile stages and eventually die.

Until 1981, the species of Halomonhystera disjuncta complex belonged to the large genus Monhystera Bastian 1865 comprising marine, limnic, brackish and soil species. Andrássy (1981) revised the non-marine part of the Monhysteridae family and established new genera to accommodate some limnic-terrestrial species of Monhystera. In particular, Andrássy (1981) erected a new genus named Geomonhystera Andrássy 1981, which is characterized by a very posterior position of vulva (at $80 \%$ of the body length) and a long, heavily muscular rectum. The genus included a few terrestrial species often dwelling in moss and under bark. Jacobs (1987), in frame of his new and comprehensive revision of Monhysteridae, created the new genus Thalassomonhystera Jacobs 1987 for the majority of marine Monhystera species. However, some marine monhysterid species with a far posterior position of the vulva, i.e., Monhystera disjuncta and related species M. ambiguoides, M. antarctica, M. chitwoodi, M. paradisjuncta, $M$. socialis and $M$. uniformis, have been transferred by Jacobs (1987) to the genus Geomonhystera. Diagnosis of Geomonhystera was thus expanded. Further, Andrássy (2006) established a separate genus Halomonhystera Andrássy 2006 to accommodate allied marine and brackish species, with the type species $H$. disjuncta (Bastian 1865) (=Monhystera disjuncta Bastian 1865). In addition, the morphological and ecological unity of the genus Geomonhystera was restored. This state was also supported in the revision of Monhysteridae made by Fonseca and Decraemer (2008).

Halomonhystera disjuncta s. str. was often described by many authors from various sites of World Ocean-see registrations summarized by Gerlach and Riemann (1973) and Jacobs (1987). But specimens described from different sites may differ from one another mainly in morphometrics. Thus, body length of adults varies in different descriptions between $532-1,520 \mu \mathrm{m}$ in males and 706-2,920 $\mu \mathrm{m}$ in females. Indices of de Man "a" and "b" vary in adult males within 17-46 and 4.0-10.3, and in adult females 15-62 and 4.4-15, respectively. Organ sizes such as cephalic setae length, amphideal fovea width, distance from the apex to the amphideal fovea and the length of spicules vary less. Hopper (1969) suggested that environmental factors can influence the body size and shape of marine nematodes, particularly for widely distributed species such as $H$. disjuncta. Chitwood and Murphy (1964) also discuss morphological modifications along growth and maturing of adult specimens. Presumably, body sizes and ratios also depend upon temperature as well as nutritional conditions. Vranken et al. (1988) showed experimentally that the adult size of $H$. disjuncta, expressed in raw weight, is directly connected with the density of bacterial cells, i.e., with food supply. Adult specimens at a density of $10^{11}$ bacterial cells/ml come out seven times bigger in raw weight than at the threshold density of $10^{7}$ cells $/ \mathrm{ml}$ that still supports successful survival of the nematodes.

Different ways of reproduction were recorded for different populations of $H$. disjuncta: oviparity (Paramonov 1929, as Monhystera ambigua; De Coninck et al. 1933), ovoviviparity (Bresslau et al. 1940) and junction ovi- and ovoviviparity (Hopper 1969). The latter author described a 
population of $H$. disjuncta with oviparous and ovoviviparous females as well as females laying eggs at various stages of egg cleavage and embryonic development. Chitwood and Murphy (1964) noted age-dependent modifications in females as well as a tendency to ovoviviparity in bigger-sized females. Gerlach and Schrage (1971) found a transfer to ovoviviparity by culturing $H$. disjuncta at very low temperatures -3 to $-5{ }^{\circ} \mathrm{C}$. Extremely wide morphometric variability and multiplicity of reproduction modes create taxonomic problems with validity of related species and synonymy of $H$. disjuncta species complex. Further below, we denote the species for whom free juveniles or even embryos in uteri are depicted as viviparous and those species having eggs but not embryos in uteri as oviparous.

Some authors (Floyd et al. 2002; De Ley et al. 2005; Bhadury et al. 2006) suggested that identification of nematodes based on morphology alone may not be enough for correct species identification. Fonseca et al. (2008) defined an "integrative taxonomy" approach for marine nematology which combines interbreeding experiments and molecular phylogenetic and morphometric analysis to delineate boundaries within species complexes. Last years, molecular methods are more often used for taxonomic classification of free-living nematodes (e.g., De Ley et al. 2005; Bhadury et al. 2008). Studies on nematode populations revealed cryptic species (morphologically close or nearly identical but genetically distinct) among marine free-living nematodes as well as among many other sea animals. Derycke et al. (2005) showed that, based on mitochondrial (COI) and nuclear (ITS and D2D3) genetic data, the widespread morphospecies Pellioditis marina (Rhabditida) actually consist of four cryptic lineages within a $100 \mathrm{~km}$ range. Similarly, recent population genetic and taxonomic studies discovered complex population genetic structures and cryptospecies of what was believed to be morphospecies within a limited area-Halomonhystera disjuncta (Monhysterida) along the coast of Belgium and the Netherlands (Derycke et al. 2007) and Thoracostoma trachygaster (Enoplida) in the Californian Bight (Derycke et al. 2010a). Derycke et al. (2007) isolated five $H$. disjuncta lineages (GD1GD5) from the Westerschelde estuary and a short part of the coastline of the North Sea. These lineages show low intraspecific genetic $(<3 \%)$ and high interspecific genetic divergences $(>14 \%)$. Derycke et al. (2010b) also established a threshold for interspecific divergence. Drawings of specimens of all genetic lineages GD1-GD5 were also presented (Fonseca et al. 2008), and discrete morphological differences between lineages were observed. Discovery of cryptic species can replace an idea of a widespread variable generalist species by a conception of species complex including several more specialized species with more restricted distribution.
Subject of this paper is the description of two species related to $H$. disjuncta which thrive in high abundances in two different habitats. The first habitat is the Håkon Mosby mud volcano (HMMV) in the Barents Sea at a depth $1,280 \mathrm{~m}$. The dominant species forms a dense monospecific and homogeneous population at the bacterial mats close to the central zone of the caldera. In a previous work on HMMV meiobenthos, the species has been denoted as Geomonhystera disjuncta (Van Gaever et al. 2006) or Halomonhystera disjuncta (Portnova et al. 2011). The species became a subject of a comprehensive study involving molecular phylogenetic analysis (based on four molecular markers, one mitochondrial gene $\mathrm{COI}$ and three nuclear ribosomal genes ITS, $18 \mathrm{~S}$ and the D2D3 region of 28S), and morphometrics (Van Campenhout et al. 2014). The results were as follows: (1) the HMMV nematode is an endemic lineage compared to the shallow-water relatives with different morphometric features; (2) HMMV nematode is embedded within the shallow-water complex revealed by Derycke et al. (2007) providing evidence for a deep-sea invasion of nematodes from shallow-water regions; (3) COI genetic divergence between HMMV and shallow-water nematodes ranges between 19.1 and $25.2 \%$ showing that the dominant HMMV nematode is a distinct new species. In this connection, one of the goals of this work is to provide a taxonomic morphological diagnosis of HMMV nematode as a new species.

The second habitat is a huge accumulation of detached kelp at a depth $15-18 \mathrm{~m}$ in the White Sea, North Russia (Tzetlin et al. 1997; Mokievsky et al. 2005). Subsurface layer of the accumulation is infested with nematodes belonging to the Halomonhystera disjuncta complex, which are distinguishable by greater body size. These nematodes were studied with light and SEM microscopy. In addition, a molecular phylogenetic analysis based on the same markers as for the HMMV nematodes was performed. Here, we provide a morphological and molecular genetical survey of this population.

The paper further consists of an analysis of described morphospecies of Halomonhystera with a revision of diagnoses and species composition of the genus.

\section{Materials and methods}

Nematode isolation, preparation, light and SEM microscopic observation

Samples have been taken at the Håkon Mosby Mud Volcano (HMMV), Barents Sea, during Arctic Ocean Expedition ARK XVIII/1 with the German research ice-breaker $\mathrm{R} / \mathrm{V}$ POLARSTERN in summer 2002 (Soltwedel et al. 2005) (Station PS62/263a, date 20.08.2002, latitude 
$72^{\circ} 00.048^{\prime} \mathrm{N}$, longitude $14^{\circ} 43.504^{\prime} \mathrm{E}$ (southern rim of the volcano), depth $1,288 \mathrm{~m}$, oxygen concentration $300.1 \mu \mathrm{mol} \mathrm{O} \mathrm{O}^{-1}$, bacterial mat). Nematodes of the top centimeter $(0-1 \mathrm{~cm})$ were used in further analysis. Sediment samples were fixed in $7 \%$ formalin on board. For counting and picking up meiofauna, sediment samples were stained with Rose Bengal and washed through a set of sieves with mesh sizes of 500, 250, 125, 65 and $32 \mu \mathrm{m}$.

Samples from the detached kelp accumulation in the White Sea $\left(66^{\circ} 33^{\prime} \mathrm{N}\right.$ and $\left.33^{\circ} 06^{\prime} \mathrm{E}\right)$ were taken in July 1996 by divers. At the surface, the samples of the algal debris were fixed with $4 \%$ formalin and in a few hours washed through a sieve with a mesh size about $90 \mu \mathrm{m}$.

Extracted nematodes were placed in vials with Seinhorst solution (70 parts distilled water, 29 parts $95 \%$ ethanol and 1 part glycerin) and gradually proceeded to pure glycerin by slow evaporation of alcohol and water in thermostat at $40{ }^{\circ} \mathrm{C}$. The specimens were then mounted into permanent glycerin slides with glass beads as spacers and sealed with beewax-paraffin. Observations, measuring, drawing and taking pictures were done with microscope Leica DM 5000. Specimens for scanning electron microscopy were processed with a critical point dryer, covered with a mixture of platinum and palladium and studied with the scanning microscope Hitachi S-405 (Tokyo, Japan) at $15 \mathrm{kV}$ voltage.

\section{DNA sequence data}

Samples from the HMMV for molecular analysis were frozen in liquid nitrogen onboard and stored at $-80{ }^{\circ} \mathrm{C}$. DNA was extracted from 30 specimens from each of the three different geographical sites within the HMMV. All the procedures and results are described by Van Campenhout et al. (2014) in detail. Genbank accession numbers are as follows: for COI: HF572956, HF572957, HF572959, HF572960 and HF572966; for ribosomal 18S gene: HF572952; for ITS: HF572967 and for D2D3: HF572953.

Nematodes from the White Sea have been isolated from algal debris and stored in ethanol (95\%). Thirty individuals were manually picked out, and their DNA was extracted following the procedure of Derycke et al. (2005). After DNA preparation, we successfully amplified $365 \mathrm{bp}$ of the mitochondrial cytochrome oxidase I (COI) gene with primers JB2_HD_HMMV and JB25_HD_HMMV for 20 WS specimens. In addition, three nuclear sequences, the Internal transcribed spacer (ITS) and the D2D3 region of $28 \mathrm{~S}$ from the four specimens and the first ca. $900 \mathrm{bp}$ of $18 \mathrm{~S}$ from three specimens for which we had both ITS and D2D3 sequence fragments, were amplified. The ITS fragment (ca. 900 bp) was amplified with primers Vrain2F and Vrain2R, whereas the D2D3 (ca. 300 bp) sequence fragment was amplified with primers D2/F1 and D3b. Finally, the $18 \mathrm{~S}$ sequence fragment was amplified with primers G18S4 and 4R. Primer sequences and thermocycling conditions were the same as described in Van Campenhout et al. (2014). All gene fragments were bidirectionally Sanger sequenced by Macrogen Inc. (http://www.macro gen.com) with the above described primers. Genbank accession numbers of WS species are KF846532KF846536.

\section{Sequence data processing}

Sequence chromatograms from all four gene fragments were analyzed with Seqman (lasergene ${ }^{\circledR}$ DNASTAR) followed by removal of the primer part. Published COI, ITS, D2D3 and 18S sequences from the dominant HMMV nematode (Van Campenhout et al. 2014) and from the five cryptic Westerschelde species revealed within $H$. disjuncta morphospecies (Derycke et al. 2007) were added to the respective dataset before alignment with ClustalX v1.74 (Thompson et al. 1997). Furthermore, a Diplolaimelloides meyli (AM748759.1) sequence was added to the COI alignment. The incongruence length difference (ILD) test (Mickevich and Farris 1981) in PAUP was used to investigate whether the different nuclear gene fragments could be combined in one analysis. Because we lacked $18 \mathrm{~S}$ sequences for several $H$. disjuncta nematodes for which we had both ITS and D2D3 sequences, we did not add the $18 \mathrm{~S}$ sequence to the concatenated dataset (ITS-D2D3) and was therefore analyzed separately. G-blocks (Castresana 2000) were used to investigate the reliability of variable positions within the $18 \mathrm{~S}$ and the concatenated (ITS-D2D3) alignment.

Prior to phylogenetic tree construction, Modeltest 3.7 (Posada and Crandall 1998) using the Akaike information criterion (Posada and Buckley 2004) was used to determine the evolutionary models for phylogenetic tree constructions. The models selected for COI, ITS-D2D3 and 18S were $\operatorname{TrN}+\mathrm{I}+\mathrm{G}$ (Tamura and Nei 1993), GTR + G (Tavaré 1986) and GTR + I, respectively. Maximum parsimony (MP), neighbor-joining (NJ) and maximum likelihood (ML) phylogenetic trees were calculated in PAUP4*b10 (Swofford 1998) using heuristic searches and a tree-bisection-reconnection branch-swapping algorithm (10,000 rearrangements), and a random stepwise addition of sequences in 100 replicate trials. One tree was held at each step. Bootstrap values for MP, NJ and ML were inferred from 1,000, 1,000 and 100 replicates, respectively. In addition to MP, NJ and ML phylogenetic tree methods, a Bayesian analysis (BA) was performed in MrBayes v3.2 (Ronquist et al. 2012). Four independent Markov chains were run for 500,000 generations, with a tree saved every 100th generation. The first 1,000 trees were discarded as burn-in. The best model for Bayesian analysis (BA) was 
determined with MrModeltest 2.2 (Nylander 2004) using the Akaike information criterion. The selected models for COI, ITS-D2D3 and 18S were HKY + I + G, GTR + G and GTR + I.

Maximum and minimum pairwise uncorrected p-distances were calculated using MEGA 5.1 (Tamura et al. 2011). Insertions and deletions were pairwise deleted.

\section{Taxonomy}

\section{Order MONHYSTERIDA Filipjev 1929}

\section{Family MONHYSTERIDAE de Man 1876}

In the recent version of Monhysteridae classification (Jacobs 1987; Fonseca and Decraemer 2008), two subfamilies were established: the Monhysterinae, including species with a funnel-shaped buccal cavity, and Diplolaimellinae, comprising species possessing a double buccal cavity. The subfamily Diplolaimellinae is further divided into two tribes, Diplolaimellini and Geomonhysterini. Andrássy (2006) has not discussed the Monhysteridae classification of Jacobs (1987) and not specified the position of Halomonhystera within a tribe or subfamily. Fonseca and Decraemer (2008) have placed Halomonhystera into the tribe Geomonhysterini together with other marine and brackish genera Cryonema Tchesunov and Riemann 1995, Hieminema Tchesunov and Portnova 2005 and Monhystrella Cobb 1918. They also provided a list of eleven known species of Halomonhystera and a dichotomous key for their identification.

The most evident feature for Halomonhystera characterization is the position of the vulva, which is far posterior to the midbody and very close to the anus. Halomonhystera species also share other morphological traits such as very short outer labial and cephalic setae, the presence of lateral postamphideal setae, a sclerotized cylindro-conical buccal cavity, a distinct renette cell and a ventral pore close to the cephalic apex, differentiation of the anteriormost portion of the midgut as a progaster, a conical tail, a sclerotized hind wall of the vagina, relatively short arcuate knobbed spicules and gubernaculum with a short dorso-caudally directed apophysis. Some monhysterid species, mostly designated as Thalassomonhystera, meet all described Halomonhystera features except for the position of the vulva, which can be located more anteriorly in respect to the anus. The last character state can be in conflict with a number of other character states cited above. Because of that and because the position of the vulva can vary gradually from one species to another, those species are here transferred to the genus Halomonhystera.

Emended diagnosis of the genus Halomonhystera and species list are presented below.

\section{Halomonhystera Andrássy 2006}

Monhysteridae. Body stout to slender. Cuticle thin and optically smooth. Labial region not set off. Inner labial sensilla as papillae, outer labial and cephalic sensilla as very short setae. Amphideal fovea circular, relatively small to moderate and situated from less than one to three labial diameters from the cephalic apex. One to three lateral cervical setae situated at some distance posterior to the amphideal fovea; other somatic setae sparse, short and inconspicuous. Pharyngostoma cup- to funnel-shaped, small, with sclerotized walls. Pharynx cylindroid, evenly muscular throughout its length. Anteriormost stomach-like portion of the intestine (progaster) composed of four cells set off from posterior intestine by a constriction. Ventral pore at labial region if discernible; ventral gland cell body large and situated at anterior intestine. Female ovary long, outstretched and located to the right of the intestine; vulva often but not always located close to the anus; posterior cuticular wall of the vagina thickened and sclerotized (pars refringens vaginae) closer to the vulva. Uterus of ripe females normally filled with numerous eggs and embryos; possibly most species ovoviviparous. Male gonad long, outstretched and located to the right of the intestine. Spicules slender and arcuate, slightly knobbed posteriorly. Gubernaculum with a short dorso-caudal apophysis. One midventral preanal papilla close to the cloacal opening and two or three pair of subventral papillae on the posterior half of the tail present. Three caudal glands present, two of them very conspicuous; terminal conical spinneret with an internal funnel-like structure.

Type species: H. disjuncta (Bastian 1865) Andrássy 2006.

Annotated list of Halomonhystera morphospecies (valid species in bold print)

1. Halomonhystera ambiguoides (Bütschli 1874) sp. inq. Bütschli 1874: 27-28, Fig. 7 (Monhystera ambiguoides); Baltic Sea, Kiel Bight, Strandanwurf (rotting seaweed on strandline). De Man 1988: 8 (as synonym of Monhystera ambigua). Gerlach and Riemann (1973: 150) (as junior synonym of Monhystera disjuncta). Jacobs 1987: 99-100 (as Geomonhystera ambiguoides). Andrássy 2006: 13, 14 (Halomonhystera ambiguoides). Original description is based on a single female and provided with one picture of anterior body but lacks some necessary details (buccal cavity looks rather as that of Monhystera s.str. type) and dimensions (such as length of anterior setae, width of amphideal fovea, distance from head apex to amphideal fovea). The species was considered by de Man (1988) as a possible synonym of M. ambigua and 
by Gerlach and Riemann (1973) as a synonym of Monhystera disjuncta. However, Andrássy (2006) and then Fonseca and Decraemer (2008) regarded the species as valid. Andrássy (2006) summarized the description of Bütschli (1874) and indicated that $H$. ambiguoides is similar to $H$. cameroni in position of the amphideal fovea at a distance of three labial diameters from the anterior end and by relatively long anterior setae (about 1/4 of the labial width, according to Fig. 7 in Bütschli (1874)). We consider this species as species inquirenda because of an incomplete original diagnosis (lack of males) and the absence of redescriptions from the type locality.

2. Halomonhystera antarctica (Cobb 1914). Cobb (1914: 21, fig. (Monhystera antarctica); Antarctica, Cape Royds. Wieser 1956: 99, 104 (as junior synonym of Monhystera parva). Jacobs 1987: 100 (as Geomonhystera antarctica). Andrássy 2006: 14 (Halomonhystera antarctica). The species was originally described on the base of one female and one male. Andrássy (2006) and then Fonseca and Decraemer (2008) considered this species valid. Andrássy (2006) mentioned distinctive features of the species such as exceedingly short and fine anterior setae, relatively large (1/3 c.b.d.) amphideal fovea fairly close to the cephalic apex and the very short tail.

3. Halomonhystera bathislandica (Riemann 1995) comb. n. Riemann 1995: 717-723, Figs. 1, 2, 3, 4 (Thalassomonhystera bathislandica); northeastern Atlantic, depth about 4,000 m, in gelatinous phytodetritus aggregates above bottom surface.

4. Halomonhystera cameroni (Steiner 1958). Steiner 1958: 269-278, Figs. 1-14, Table 1 (as Monhystera cameroni); collected on maxillipeds and mandibles of mysidacean and decapod crustaceans in the Gulf of St. Lawrence. Jacobs 1987: 103 (as synonym of Geomonhystera disjuncta). Andrássy 2006: 14 (Halomonhystera cameroni).

5. Halomonhystera chitwoodi (Steiner 1958). Chitwood 1951: 653, Fig. 11e-f (as Monhystera socialis, nec M. socialis sensu Bütschli 1874); Gulf of Mexico (Texas, in Sargassum). Steiner 1958: 275 (as Monhystera chitwoodi) Jacobs 1987: 100 (as Geomonhystera chitwoodi). Andrássy 2006: 15 (Halomonhystera chitwoodi).

6. Halomonhystera continentalis Andrássy 2006. Andrássy 2006: 20-23, figs A-F; Antarctica, Highway Lake, semi-saline lake of marine origin, microbial mat.

7. Halomonhystera disjuncta (Bastian 1865). Records and synonymy of this often cited species are summarized in Gerlach and Riemann (1973), Jacobs (1987) and Andrássy (2006).
8. Halomonhystera fisheri (Zekely et al. 2006) comb. $\mathbf{n}$. Zekely et al. 2006: 31-35, Figs. 4, 5A-L, 6A-L, Table 1 (Thalassomonhystera fisheri); East Pacific Rise, Tica hydrothermal site, 2,500 m, associated with vestimentiferans Riftia pachyptila.

9. Halomonhystera glaciei (Blome and Riemann 1999). Blome and Riemann 1999: 16-19, Figs. 1, 2 (Geomonhystera glaciei); Antarctica, Bellingshausen Sea, sea ice). Andrássy 2006: 16 (Halomonhystera glaciei).

10. Halomonhystera halophila Andrássy 2006. Andrássy 2006: 17-20, Figs. 1A-D, 2A-C; Antarctica, Princess Elizabeth Land, Vestfold Hills, Ace Lake, a saline lake of marine origin, microbial mat.

11. Halomonhystera hermesi sp. n. Present paper.

12. Halomonhystera hickeyi Zekely et al. 2006. Zekely et al. 2006: 36-40, Figs. 7, 8A-L, 9A-J; Pacific Ocean, East Pacific Rise, Riftia field, 2,500 m, associated with vestimentiferans Riftia pachyptila.

13. Halomonhystera islandica (De Coninck 1943) comb. n. De Coninck 1943: 207-208, Figs. 18-20 (Monhystera islandica); Iceland, brackish, wet and warm soil at the Cape Reykjanes. Lorenzen 1969: 213-214, Abb. 13 a-e (Monhystera islandica); North Sea coast, salt marsh. Jacobs 1987: 78 (as Thalassomonhystera islandica, list of records).

14. Halomonhystera paradisjuncta (De Coninck 1943) comb. n. De Coninck 1943: 204-206, Figs. 14-17 (Monhystera paradisjuncta); Iceland, small rocky basin with warm brackish water at the Cape Reykjanes. Chitwood and Murphy, 1964 (Monhystera paradisjuncta, discussion of diagnostic characters). Jacobs 1987: 98 (as Geomonhystera paradisjuncta). Andrássy 2006: 15 (as junior synonym of $H$. disjuncta). The species was described on the base of a single male and a few juveniles.

15. Halomonhystera parasitica Poinar et al. 2010. Poinar et al. 2010: 54-58, Figs. 2-9; Portugal, Aveiro Estuary, associated with intertidal amphipod crustaceans Talorchestia brito (in hemocoel and under the dorsal body-plates).

16. Halomonhystera rotundicapitata (Filipjev 1922) comb. n. Filipjev 1922: 170-171, Figs. 32a-c (Monhystera rotundicapitata); Black Sea, large stones overgrown by brown algae Cystoseira. Jacobs 1987: 21 (as Thalassomonhystera rotundicapitata). Tsalolikhin 2007: 1285 (as Geomonhystera rotundicapitata). This species was referred to Halomonhystera neither by Andrássy (2006), nor by Fonseca and Decraemer (2008). However, this species evidently relates to Halomonhystera because of short outer labial and cephalic setae, small amphideal fovea, 
conical tail, position of vulva rather close to anus (V $76 \%$ ), similar shape of spicules.

17. Halomonhystera socialis (Bütschli 1874). Bütschli 1874: 28-29, Fig. 8a-d (Monhystera socialis); West Baltic Sea, Kiel Bay, in decaying algae at coastal line. Allgén 1935: 122-123, Fig. 56 (Monhystera socialis); Baltic Sea, Öresund, Helsingör. Kreis 1963; 7-10, Fig. 4a, b (Monhystera socialis); Iceland, Eyjafjördur. Jacobs 1987: 105 (as Geomonhystera socialis). Andrássy 2006: 16 (Halomonhystera socialis). Despite the rather poor original description, the species is set apart all the other Halomonhystera species by an evident size hiatus. Original description was performed largely on a female; the male was mentioned but not measured, and male structures were not depicted except a tail and spicules.

18. Halomonhystera tangaroa Leduc 2014. Leduc 2014: 48-53, Fig. 1-3, Table 1; Southwest Pacific, summit of Tangaroa Seamount on the southern Kermadec Arc, $680 \mathrm{~m}$ water depth, byssus threads of hydrothermal vent mussels Gigantidas gladius.

19. Halomonhystera taurica (Tsalolikhin 2007) comb. n. Tsalolikhin 2007: 1283-1289, fig. (Geomonhystera taurica); Black Sea, Crimea Peninsula, vicinity of Sebastopol, Khersonesskoje Lake, salinity $35 \%$.

20. Halomonhystera uniformis (Cobb 1914). Cobb 1914: 18-19, fig. (Monhystera uniformis); Antarctica, Cape Royds. Jacobs 1987: 98 (as Geomonhystera uniformis). Andrássy 2006: 17 (Halomonhystera uniformis). The species is poorly illustrated and measured, and there is a hope to recognize the species if found somewhere. The almost only feature indicating a relation to Halomonhystera is the position of vulva close to anus ( $V=83 \%)$. Andrássy (2006) considered the species can be distinguished from other Halomonhystera species by body length $(440-460 \mu \mathrm{m}$, the smallest species within the genus), relatively long spicules (2.5 anal diameters long) and long tail $\left(c^{\prime}=6.5\right)$. Andrássy (2006) assumed Monhystera barentsi Steiner 1916 described on the base of a sole female as a junior synonym of Halomonhystera uniformis.

21. Halomonhystera vandoverae (Zekely et al. 2006) comb. n. Zekely et al. 2006: 27-31, Figs. 1, 2A-O, 3A-K, Table 1 (Thalassomonhystera vandoverae); Mid-Atlantic Ridge, Snake Pit hydrothermal vent field, associated with Bathymodiolus puteoserpentis mussel aggregations.

Halomonhystera hermesi sp.n.

Figures 1, 2, 3, 4 and 5, Table 1: morphometrics

\section{Material}

One holotype male, eight paratype males, 21 paratype females and 24 juveniles. Type specimens as permanent glycerin slides are partly deposited in the Museum of Gent University (Gent, Belgium) and are partly kept in Nematological collection of the Center of Parasitology of the A.N.Severtsov Institute of Ecology and Evolution of the Russian Academy of Sciences, Moscow, Russia. The Gent part of the collection consists of seven males, seven adult females and 24 juveniles. Gent specimens are distributed in four slides: slide 5/48 (ARK XVIII, HM 263A, B1 500-125) - two paratype males and four paratype adult females (accession number UGMD104274); slide 5/72 (ARK XVIII, HM 263A, B3 500-125)—one holotype male, one allotype female, one paratype female and three paratype juveniles (accession number UGMD104275); slide 5/80 (ARK XVIII, HM 263A, C1 500-125)—two paratype males, one paratype female and nine paratype juveniles (accession number UGMD104276); slide 5/81 (ARK XVIII, HM 263A, C1 500-125) - two paratype males and twelve paratype juveniles (accession number UGMD104277).

\section{Locality and biotope}

The Håkon Mosby Mud Volcano (HMMV) is an active mud-oozing and methane-venting seep located on the southwest Barents Sea slope $\left(72^{\circ} 00.25^{\prime} \mathrm{N} / 14^{\circ} 43.50^{\prime} \mathrm{E}\right)$ at a water depth about 1,280 m (Fig. 1a, b). The cake-shaped caldera has $1 \mathrm{~km}$ in diameter and 8-10 $\mathrm{m}$ height from the foot. The central zone of the caldera is about $200 \mathrm{~m}$ in diameter and characterized by strong reduced condition with methane concentration in the surface sediment layer reaching $12.5 \mathrm{ml} / \mathrm{l}$ (Soltwedel et al. 2005). The water just above the sediment surface is also enriched by methane $(6 \mathrm{ml} / \mathrm{l})$ (Lein et al. 2000). Temperature within the sediment at a depth of $2 \mathrm{~m}$ is over $15^{\circ} \mathrm{C}$ and at a depth $30 \mathrm{~cm} 11{ }^{\circ} \mathrm{C}$ that may suppose a strong thermal gradient at the sediment-water interface (Soltwedel et al. 2005). The free methane in sediments beside the central zone is replaced by gas hydrates: Their content may exceed $25 \%$ of sediment (Soltwedel et al. 2005). Whitish bacterial mats (Fig. 1b) cover up to $80 \%$ of the bottom outside the central zone (Soltwedel et al. 2005). $H$. hermesi thrives in very high densities at these bacterial mats (van Gaever et al. 2006).

\section{Sample site}

Arctic Ocean Expedition ARK XVIII/1 with the German research ice-breaker R/V POLARSTERN. (Station PS62/ 263a, date 20.08 .2002 , latitude $72^{\circ} 00.048 \mathrm{~N}$, longitude 
Fig. 1 Localities and habitats of two Halomonhystera species. a position of Håkon Mosbi, site of $H$. hermesi sp. n. (1) and White Sea, site of $H$. socialis (2); $\mathbf{b}$ area with whitish bacterial mat in the caldera of Håkon Mosbi, habitat of H. hermesi sp. $\mathrm{n}$.; $\mathbf{c}$ accumulation of detached kelp in the White Sea, habitat of $H$. socialis
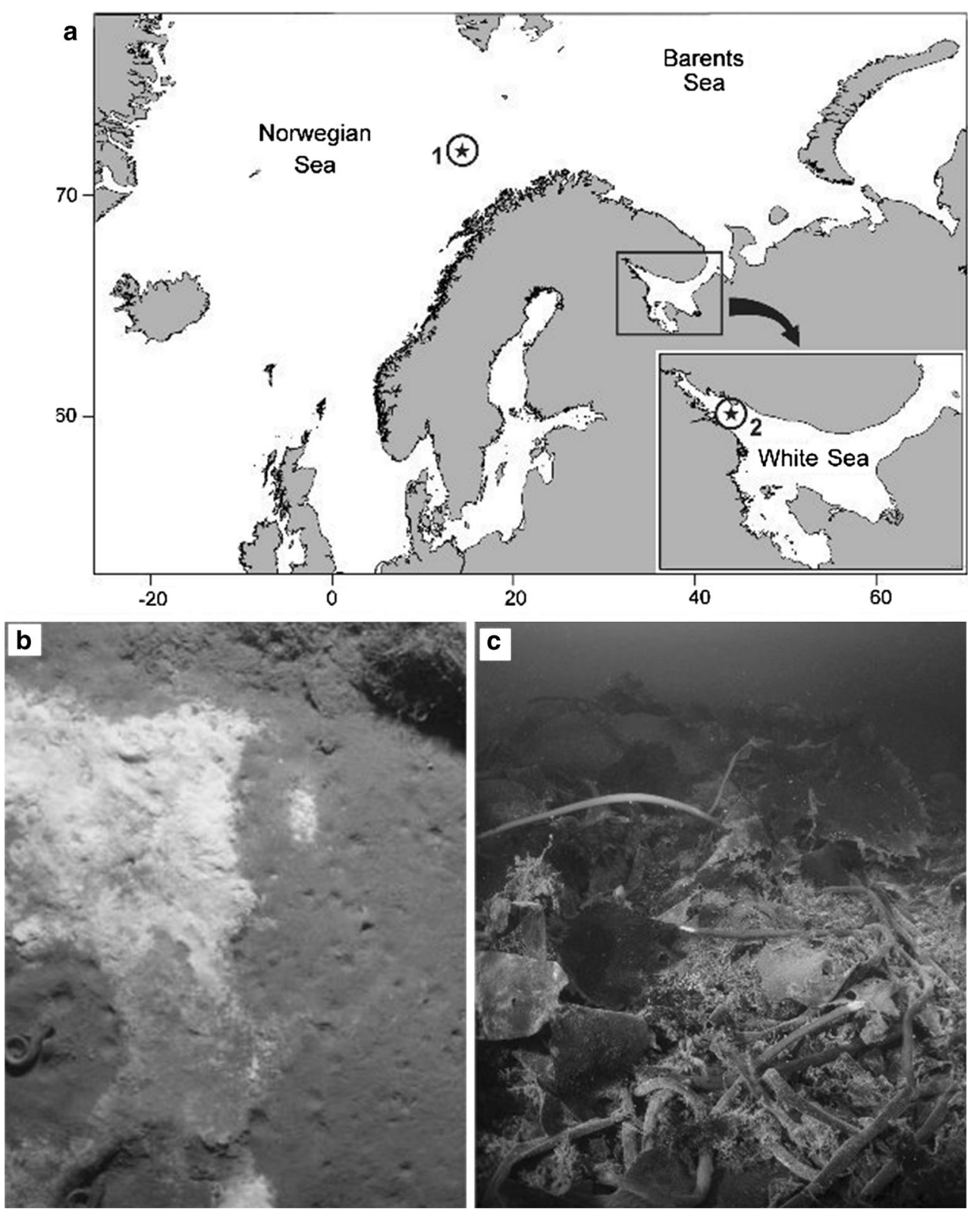

$14^{\circ} 43.504^{\prime} \mathrm{E}$ (southern rim of the volcano), depth $1,288 \mathrm{~m}$, oxygen concentration $300.1 \mu \mathrm{mol} \mathrm{O} 21-1$, bacterial mat). Nematodes were abundant in bacterial mats reaching density of 2,529 individuals $/ 10 \mathrm{~cm}^{2}$ for the $0-1 \mathrm{~cm}$ and 2,798 ind./10 $\mathrm{cm}^{2}$ for $0-5$ ind./10 $\mathrm{cm}^{2}$ (Soltwedel et al. 2005).

\section{Etymology}

The species name hermesi is linked to HERMES, the name of the research project devoted to all-round study of the Håkon Mosby phenomenon.

\section{Description}

Body rather short and stout, cylindrical to spindle shaped (Fig. 2). Cuticle smooth. Body often covered with fungi, bacteria and sticked foreign particles, very densely on perianal region where they form a fluffy muff, and sparsely on the rest of the body (Fig. 5a).

Anterior end truncated. Inner labial papillae minute and hardly discernible. Outer labial and cephalic sensilla joined in one crown of ten nearly equally short setae $(1.3-2.2 \mu \mathrm{m}$ long in both males and females, 9-18 \% c.b.d. in males and 9-16 \% c.b.d. in females). Amphideal fovea in most 


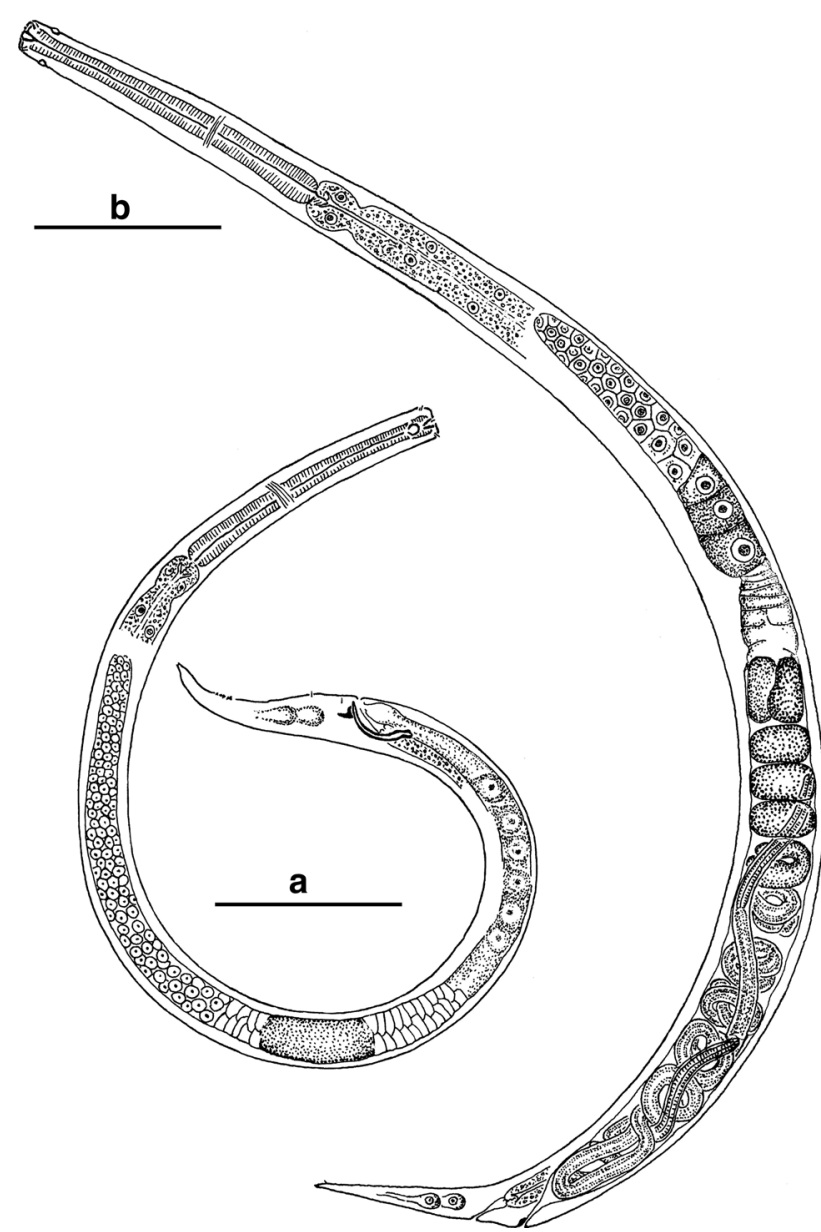

Fig. 2 Halomonhystera hermesi sp. n., paratypes, entire. a Male; b female. Scale bars $100 \mu \mathrm{m}$

specimens relatively small, circular, with distinct uninterrupted cuticular rim. But in a few specimens the fovea observed as cryptospiral with a slight posterodorsal projection; such foveas may be described as comma-like (ventrally coiled). Amphideal fovea situated posterior to the level of the buccal cavity. One or two short successive lateral cervical setae situated posterior to the amphideal fovea at a distance from the cephalic apex $28-36 \mu \mathrm{m}$ in males and 28-44.5 $\mu \mathrm{m}$ in females (Fig. 3a, b).

Somatic cuticle thickened apically. Cheilostoma short and wide, with weakly sclerotized walls. Pharyngostoma very distinct, conoid, its walls with three equal thick and solid rhabdions (Fig. 3a, b). Pharynx rather strong and wide, evenly muscular throughout its length, cylindroid and gradually widening to the posterior end. Cardia conical to spindle shaped, enveloped by intestinal tissue. Nerve ring poorly discernible, located slightly posterior to the middle of the pharynx (Figs. 2, 3c). Intestinal cells with coarse brownish granules. Ventricular region of intestine set off by a narrowing, thus shaping a progaster (Fig. 3d).
Midgut diameter at the progaster was 1.4-1.8 times greater than the midgut diameter at the narrowing just posterior to the progaster. Two anteriormost cells of the progaster, dorsal and ventral, differ from all other intestinal cells by finer granularity and paleness of their cytoplasm. Distinct and thick layer of glycocalyx in the intestinal lumen.

Ampulla of the ventral gland situated at the level of the amphideal fovea. A very thin canal extended from the ampulla to the labial region; ventral pore visible at the edge of the apex, nearly at the level of outer labial and cephalic setae crown (Fig. 3a, c). Cell body of the ventral gland presumably at the level of the anterior intestine but poorly discernible.

Single female genital branch situated at the right side of the midgut in all females observed. Female gonad consisting of terminal germinal zone with a few rows of small transparent cells with relatively big nuclei, and growth zone with one row of three to five oocytes with granular cytoplasm and well-discernible nuclei. Posterior to the oocytes, the female branch narrowed abruptly by constriction from the oviduct shaped as a truncated cone transversally plicate; there is possibly a circular sphincter in this region. The following region is a long uterus with a sequence of developing eggs and shelled embryos (Fig. 5b-f). Spherical fertilized eggs in uterus about 23-38 $\mu \mathrm{m}$ in diameter. One uterus can contain up to ten fertilized eggs and embryos still in egg shell, and usually three to five hatched juveniles. Vagina situated close to the anal opening, oblique, with slightly sclerotized posterior side (Fig. 4d). No vulvar glands visible.

Single male genital branch situated to the right side of the midgut in all males observed. Spermatozoa as tiny globular beads. Seven to eight ejaculatory gland cell bodies at either right of left side of the ejaculatory duct. Spicules slender, arcuate, anteriorly slightly cephalated, posteriorly pointed. Gubernaculum with a short dorso-caudal apophysis and lateral curved funnel-shaped pieces (Fig. 5h). A few pre- and postanal subventral tiny setae may be visible. A small midventral papilla just anterior to the cloacal opening (Figs. 3f-g, 4a-c).

Tail conical, terminal cone (spinneret) 3-5 $\mu \mathrm{m}$ long with an internal slightly curved funnel-like cuticular structure within the spinneret (Fig. 4e). A minute seta can be present at the base of the spinneret. In males, there are three pairs of small conical subventral papillae located very close to one another on the posterior third of the tail.

\section{Content of the alimentary tract}

Almost all specimens contain some granular material and spherical drops in lumen of the midgut (Fig. 5g). Some specimens have lumps of granular material in the buccal cavity. 
Fig. 3 Halomonhystera hermesi sp. n., anterior body structures and copulatory apparatus. a holotype male, head region; b paratype female, head region; c paratype male, anterior body; $\mathbf{d}$ paratype male, posterior pharynx, cardia and progaster; e-g pericloacal region and copulatory apparatus of holotype male (e), paratype males (f, g). Scale bars $\mathbf{a}, \mathbf{b}, \mathbf{e}-$ g $10 \mu \mathrm{m} ; \mathbf{c} 50 \mu \mathrm{m} ; \mathbf{d} 20 \mu \mathrm{m}$
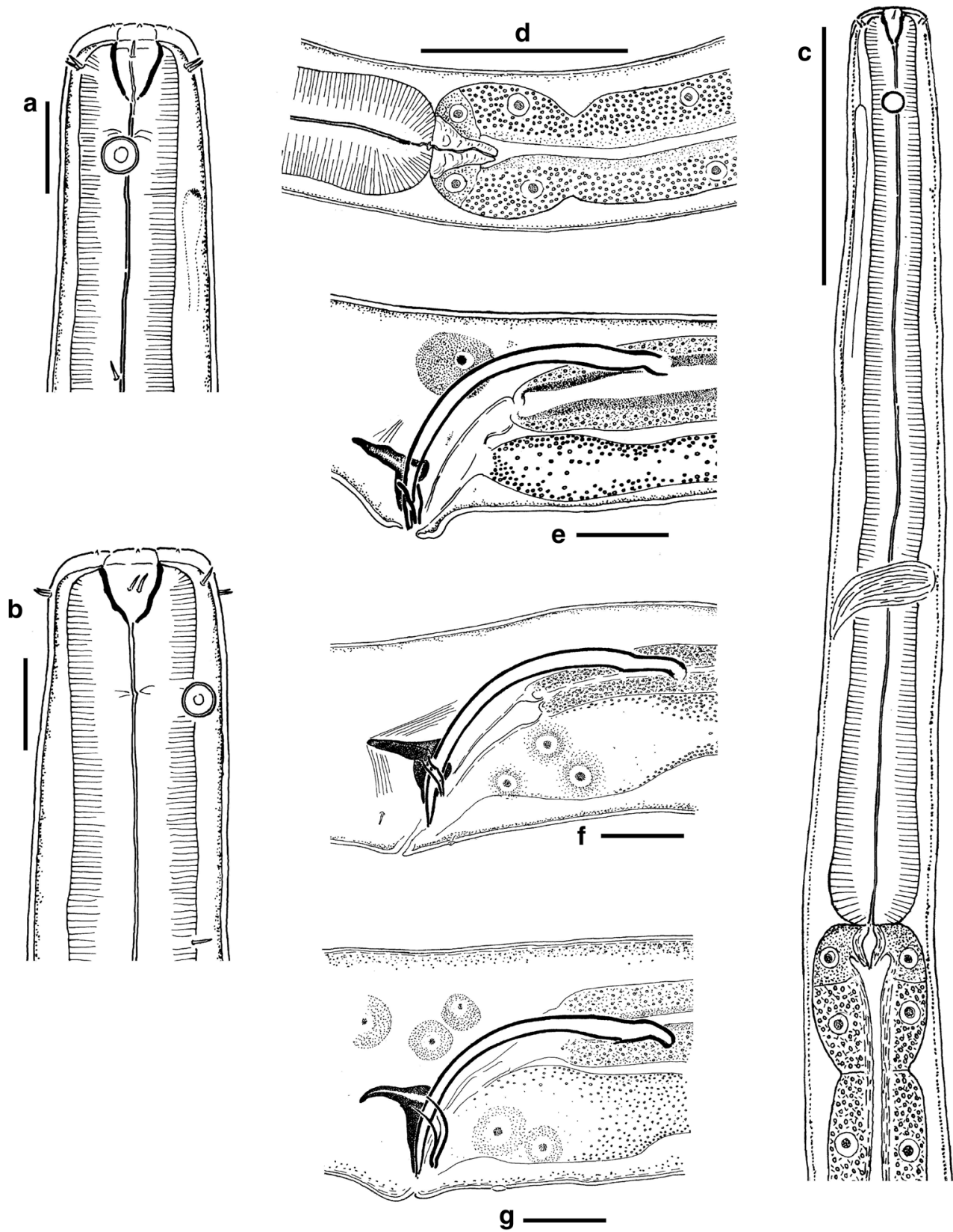

\section{Diagnosis}

Halomonhystera. Body length $635-1,082 \mu \mathrm{m}$, body length divided by maximum body diameter $18-39$, body length divided by length of the pharynx $4-6$, body length divided by tail length 7.9-10, tail length divided by anal body diameter 3-4.2 in males and 3.2-7 in females, distance of vulva from anterior end as percentage of body length 76.9-90.6\%, tail length divided by distance vulvaanus 2-3.5. Body rather cylindrical, stout; cephalic end wide and truncate. Amphideal fovea width $20-24 \%$ of corresponding body diameter in males and $16-30 \%$ in females. Lateral postamphideal setae very short and hardly discernible. Pharyngostoma well defined, conical, with sclerotized walls. Viviparous. Male with a small midventral preanal papilla and three successive pairs of minute subventral papillae close together on posterior half of the tail. Spicules 38-50 $\mu \mathrm{m}$ long. Gubernaculum with short dorso-caudal apophysis.

\section{Molecular data}

Nuclear (18S, ITS and D2D3 region of 28S) sequences were obtained for 5-10 specimens from three locations 
Fig. 4 Halomonhystera hermesi sp. n., posterior body structures. a-d Tail region and copulatory apparatus of holotype male (a) and paratype males $(\mathbf{b}, \mathbf{c})$ and tail region in paratype female (d); e tail tip of a paratype male. Scale bars ad $50 \mu \mathrm{m} ;$ e $10 \mu \mathrm{m}$
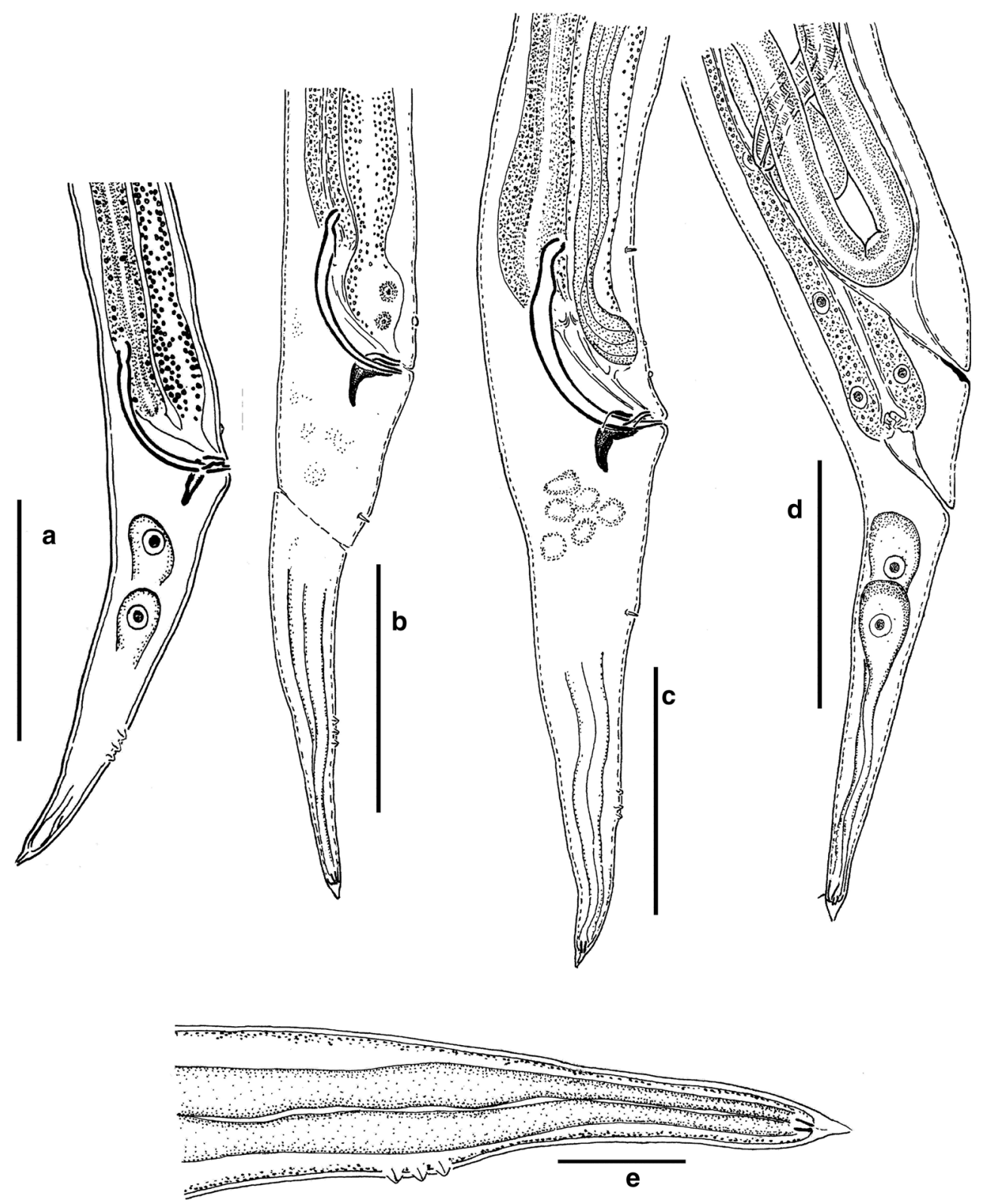

within the Håkon Mosby mud volcano (HMMV) (North, South East and South West), while mitochondrial sequences cytochrome oxidase subunit I (COI) was obtained for ca. 30 specimens for each of these locations (Van Campenhout et al. 2014). The divergence of 18S, ITS-D2D3 gene between lineages GD1-5 and $H$. hermesi can be found in Tables 7 and 8. Phylogenetic trees based on the concatenated nuclear markers (ITS and D2D3) as well as $18 \mathrm{~S}$ phylogenetic trees revealed that $H$. hermesi is genetically more close to shallow-water $H$. disjuncta species GD1 and GD4 of Derycke et al. (2007) (Van Campenhout et al. 2014). Concatenated (ITS-D2D3) and 18 S nuclear sequences are, respectively, 9.3-9.5 and 2.4-2.9\% divergent from those of GD1-GD4, and, respectively, 14.0-15.5 and $8.9-19.3 \%$ divergent from those of GD2, GD3 and GD5. The close genetic relation between $H$. hermesi and GD1-GD4 was well supported (Van Campenhout et al. 2014).

Intraspecific divergence ranges of COI sequences were small (0.3-1.0\%), and five haplotypes were identified. COI DNA sequences have a divergence of 19.1-25.2\% from those of GD1-5. A COI-based phylogenetic tree could not resolve the phylogenetic relations between GD1-5 and H. hermesi (Van Campenhout et al. 2014).

COI accession numbers: HF572956, HF572957, HF572959, HF572960 and HF572966. 18S accession number: HF572952. ITS accession number: HF572967. D2D3 accession number: HF572953. 

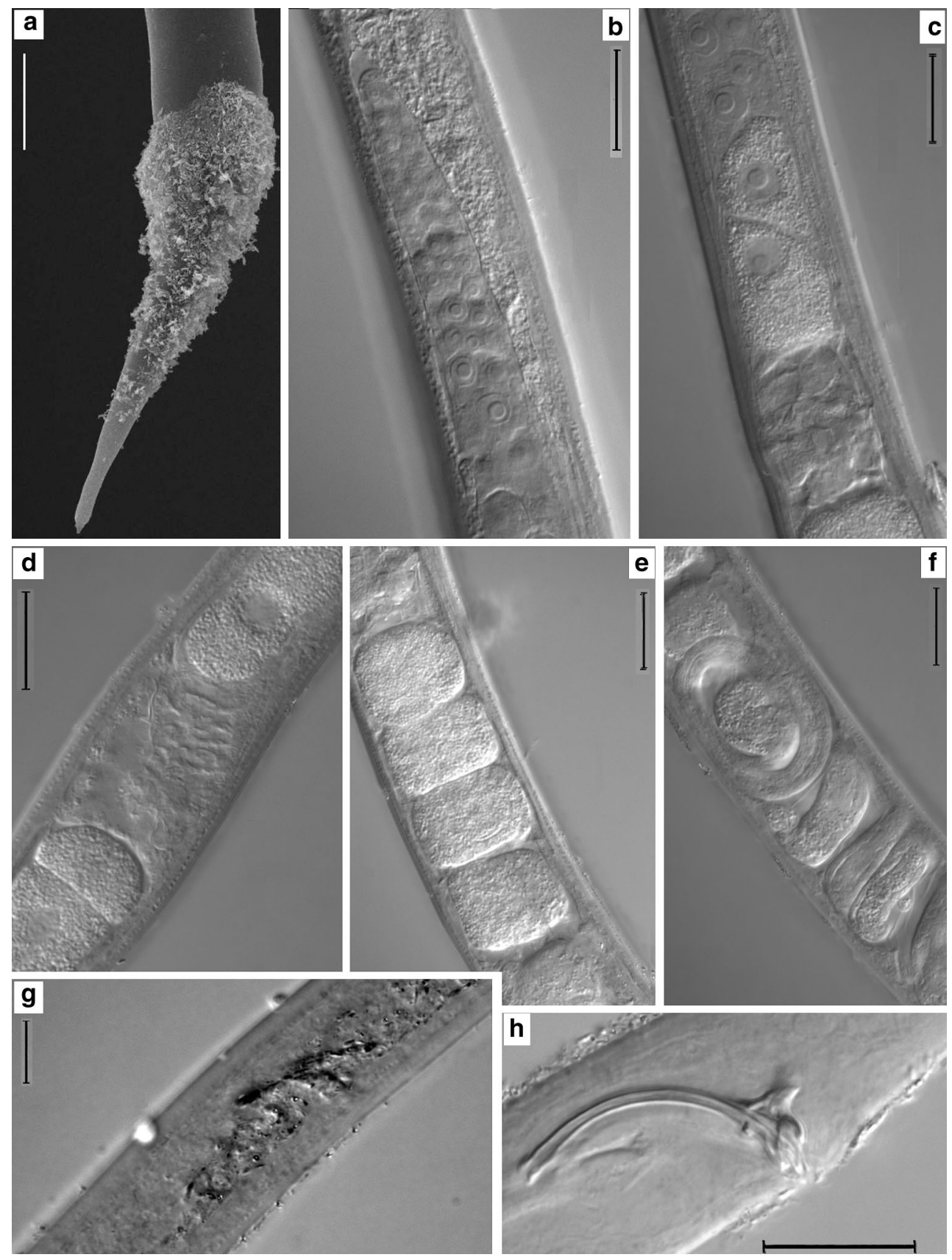

Fig. 5 Halomonhystera hermesi sp. n., details. a Posterior body densely covered with foreign particles sticked (SEM); $\mathbf{b}$ anterior tip of the ovary; c posterior ovary and oviduct; $\mathbf{d}$ ripest oocyte, oviduct and cleaved egg; e fertilized eggs in uterus; f embryos still with egg shells; g content in the midgut; $\mathbf{h}$ copulatory apparatus. Scale bars $20 \mu \mathrm{m}$

posterior position of vulva $(\mathrm{V}>80 \%)$ make up the $H$. disjuncta species complex. Apart from species with very small ( $H$. continentalis, $H$. islandica, $H$. paradisjuncta, $H$. uniformis) and very long (H. glaciei, H. socialis) bodies, other Halomonhystera species are very similar to one another but differ in very fine morphometric characters and in some qualitative traits concerning copulatory structures in males. Unfortunately, such promising trait as number 
Table 1 Morphometrics of the type specimens Halomonhystera hermesi sp. $\mathrm{n}$

\begin{tabular}{|c|c|c|c|}
\hline Character & $\begin{array}{l}\text { Holotype } \\
\text { male }\end{array}$ & $\begin{array}{l}\text { Paratype } \\
\text { males } \\
(n=8)\end{array}$ & $\begin{array}{l}\text { Paratype } \\
\text { females } \\
(n=21)\end{array}$ \\
\hline$L$ & 781 & $688-1,038$ & $635-1,082$ \\
\hline$a$ & 28.5 & $23.2-39.3$ & $17.9-27.2$ \\
\hline$b$ & 4.91 & $3.99-6.19$ & $4.06-5.93$ \\
\hline$c$ & 8.31 & $7.86-10.6$ & $8.42-11.3$ \\
\hline$c^{\prime}$ & 3.32 & $3.00-4.18$ & $4.55-5.48$ \\
\hline$V$ & - & - & $84.9-89.3$ \\
\hline Distance from vulva to anus & - & - & $19.0-30.4$ \\
\hline $\begin{array}{l}\text { Distance from vulva to anus } \\
\text { divided by tail length }\end{array}$ & - & - & $0.23-0.39$ \\
\hline $\begin{array}{l}\text { Distance from vulva to anus } \\
\text { divided by anal body } \\
\text { diameter }\end{array}$ & - & - & $1.14-1.81$ \\
\hline $\begin{array}{l}\text { Body diameter at the level of } \\
\text { cephalic setae }\end{array}$ & 13.5 & $11.5-15.8$ & $11.5-17.4$ \\
\hline $\begin{array}{l}\text { Body diameter at the level of } \\
\text { amphideal foveas }\end{array}$ & 16.5 & $14.6-18.2$ & $14.8-20.0$ \\
\hline $\begin{array}{l}\text { Body diameter at level of } \\
\text { nerve ring }\end{array}$ & 20.7 & $20.7-23.4$ & $23.3-28.0$ \\
\hline $\begin{array}{l}\text { Body diameter at level of } \\
\text { cardia }\end{array}$ & 23.3 & $21.4-29.0$ & $24.2-30.4$ \\
\hline Midbody diameter & 27.4 & $23.0-41.7$ & $32.8-50.0$ \\
\hline Anal body diameter & 28.3 & $21.9-32.7$ & $16.0-19.8$ \\
\hline Width of amphideal fovea & 3.6 & $3.0-4.2$ & $3.3-4.0$ \\
\hline $\begin{array}{l}\text { Width of the amphideal } \\
\text { fovea, as percentage of } \\
\text { c.b.d., } \%\end{array}$ & 21.8 & $19.8-24.1$ & $17.0-27.5$ \\
\hline $\begin{array}{l}\text { Distance from cephalic apex } \\
\text { to anterior rim of } \\
\text { amphideal fovea }\end{array}$ & 12.1 & $10.2-17.6$ & $10.0-14.6$ \\
\hline $\begin{array}{l}\text { Distance from cephalic apex } \\
\text { to anterior rim of } \\
\text { amphideal fovea divided by } \\
\text { body diameter at level of } \\
\text { cephalic setae }\end{array}$ & 0.90 & $0.73-1.43$ & $0.71-0.96$ \\
\hline Total stoma length & 7.50 & $6.4-8.5$ & $6.4-8.0$ \\
\hline Maximal stoma width & 3.60 & $3.4-6.0$ & $4.5-7.0$ \\
\hline Spicule's length along chord & 34.5 & $31.8-36.7$ & - \\
\hline Spicule's length along arch & 43.2 & $38.7-50.0$ & - \\
\hline $\begin{array}{l}\text { Length of apophysis of the } \\
\text { gubernaculum }\end{array}$ & 11.0 & $4.8-11.0$ & - \\
\hline Length of the vagina & - & - & $16.8-26.0$ \\
\hline Length of the rectum & - & - & $13.0-20.0$ \\
\hline
\end{tabular}

Measures in $\mu \mathrm{m}$ except for ratios

and position of pre- and postcloacal papillae in males is not studied in all species. H. hermesi differs from each closely related species in at least one non-overlapping mensural character (see Tables 2, 3). H. hermesi fits in greater number of characters to $H$. disjuncta, $H$. halophila, $H$. parasitica and $H$. tangaroa than other related species, but differs from them in values of indices $b, c, c^{\prime}$ and relative distance from cephalic apex to the amphideal fovea. Additionally, $H$. halophila differs from $H$. hermesi in having only one pair subventral papillae close to the tail tip, $H$. parasitica in two widely separated pairs of postcloacal subventral papillae, $H$. tangaroa in four pairs of subventral postcloacal papillae, one pair postcloacal and three pairs near tail tip, versus three pairs close to one another. Perspectively, promissory characters for species discrimination within $H$. disjuncta species complex may become position of the amphideal fovea as a distance from the cephalic apex and position of subventral papillae on the male tail which may be not very distinctly visible (Table 4).

Thorough morphological comparison with genetic lineages GD1-GD5 revealed by Derycke et al. (2007) and designated as cryptotaxa or cryptospecies is now hardly possible. Representatives were depicted, and some morphometric data were presented by Fonseca et al. (2008). Structural differences are not clear or at least not evident between the lineages (it is known that some fine structure, e.g., preanal papilla may be clearly visible in some individuals and indiscernible in others within the same population). As for morphometrics, H. hermesi males differ from males of all lineages in relatively longer tail length expressed in index "c" and from all lineages, except GD2 males, in relatively shorter pharynx length (Tables 5). H. hermesi females, but not males, also differ from all lineages in relative distance from the cephalic apex to the anterior edge of the amphideal fovea expressed in cephalic diameters (Table 6). We expect, other fine structural characters differentiating cryptospecies of $H$. disjuncta complex may be found later on. Van Campenhout et al. (2014) did, however, supply morphometric features to discriminate $H$. hermesi from GD1 to GD5. These features clearly revealed to be statistically significantly different between $H$. hermesi and GD1-5.

Halomonhystera socialis (Bütschli 1874)

Figures 6, 7, 8, 9 and 10, Table 6.

\section{Locality and biotope}

White Sea (Northern Russia), Karelian Coast of the Kandalaksha Bay, vicinity of the White Sea Biological Station of Moscow State University, depth 12-15 m, accumulation of detached decaying kelp, July 1996 (Fig. 1a, c).

The stable long-term accumulation of detached kelp is situated at the distance $50-100 \mathrm{~m}$ from the coastline and 
Table 2 Comparison of Halomonhystera species (males)

\begin{tabular}{|c|c|c|c|c|c|c|c|c|c|c|}
\hline \multirow[t]{2}{*}{ Species } & \multicolumn{10}{|l|}{ Characters } \\
\hline & $L$ & $a$ & $b$ & $c$ & $c^{\prime}$ & $\begin{array}{l}\text { Width of } \\
\text { the } \\
\text { amphideal } \\
\text { fovea (in } \\
\text { brackets, as } \\
\text { percentage } \\
\text { of c.b.d., } \\
\% \text { ) }\end{array}$ & $\begin{array}{l}\text { Distance } \\
\text { from } \\
\text { cephalic } \\
\text { apex to } \\
\text { anterior } \\
\text { rim of } \\
\text { amphideal } \\
\text { fovea, } \mu \mathrm{m}\end{array}$ & $\begin{array}{l}\text { Distance from } \\
\text { cephalic apex to } \\
\text { anterior rim of } \\
\text { amphideal fovea } \\
\text { divided by body } \\
\text { diameter at level of } \\
\text { cephalic setae }\end{array}$ & $\begin{array}{l}\text { Total } \\
\text { stoma } \\
\text { length } \\
(\mu \mathrm{m})\end{array}$ & $\begin{array}{l}\text { Spicule's } \\
\text { length } \\
(\mu \mathrm{m})\end{array}$ \\
\hline antarctica & 900 & 33 & $\underline{7.5}$ & 11 & 3.6 & (33) & $?$ & $1.3-1.4$ & $?$ & $34-40$ \\
\hline bathislandica & $\underline{572-684}$ & $36-39$ & $5.3-6.2$ & $\underline{7.4-7.5}$ & $\underline{5.5-6}$ & 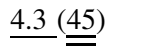 & 15 & $\underline{2}$ & $\underline{6}$ & $\underline{22}$ \\
\hline cameroni & 1,054 & 40 & $\underline{7.3}$ & 11 & $3.3-3.6$ & $(25)$ & $?$ & $\underline{2-3}$ & 8 & 38 \\
\hline chitwoodi & $\underline{1,450}$ & 34 & $\underline{9.8}$ & 9.8 & $\underline{4.4}$ & (25) & 11 & 1 & $?$ & 42 \\
\hline continentalis & $\underline{420-560}$ & $20-23$ & $5-5.6$ & $10-11$ & $\underline{2.1-2.5}$ & $\underline{(33)}$ & $9-12$ & $1.2-1.8$ & $\underline{4-6}$ & $\underline{26-30}$ \\
\hline disjuncta & $800-1,500$ & $24-35$ & $\underline{6.2-10}$ & $\underline{11-20}$ & $2-3$ & $(25)$ & $?$ & $<2$ & $?$ & $27-42$ \\
\hline fisheri & $680-860$ & $28-41$ & $\underline{6.7-7.2}$ & $9.1-9.9$ & $\underline{4.3-4.8}$ & $\underline{(50)}$ & $12-14$ & $\underline{2.14 \mathrm{calc}}$ & 5 & $\underline{27-29}$ \\
\hline glaciei & $\underline{2,200-2,500}$ & $\underline{81-91}$ & $\underline{7.3-8.2}$ & $\underline{11-20}$ & $\underline{6.3}$ & $\underline{(29)}$ & $\underline{26}$ & $\underline{2-2.5}$ & $?$ & $36-40$ \\
\hline halophila & $820-1,330$ & $\overline{29-38}$ & $\underline{7-10}$ & $\underline{11-13}$ & $2.7-3.6$ & $(25)$ & $\underline{22-30}$ & $0.8-1.2$ & $\underline{10-12}$ & $44-53$ \\
\hline hermesi sp. n. & $688-1,038$ & 23-39 & $3.9-6.2$ & 7.9-10.6 & $3-4.2$ & $\begin{array}{l}3-4 \\
\quad(20-24)\end{array}$ & 11-18 & 0.7-1.4 & $6.4-8.5$ & $32-50$ \\
\hline hickeyi & $605-740$ & $30-34$ & $\underline{6.1-6.7}$ & $10-11$ & 3.3 & $\underline{\underline{50}})$ & 11 & 1.52 calc & $?$ & $\underline{25-30}$ \\
\hline islandica & $\underline{380-400}$ & $26-29$ & $5.1-5.5$ & $7.7-8$ & $\underline{4.3-4.7}$ & $\underline{(\overline{33}-35)}$ & $\underline{9.5-10.3}$ & 1.65 calc & $\underline{3}$ & $\underline{14-19}$ \\
\hline paradisjuncta & $\underline{600}$ & 27 & 5.4 & 10 & $\underline{2.8}$ & $(20-25)$ & $12-18$ & 1.56 calc & $\underline{5}$ & \\
\hline parasitica & $900-1,100$ & $25-29$ & $4.8-5.7$ & $8-9$ & $\begin{array}{l}4.2 \\
\text { calc }\end{array}$ & 4 (22 calc) & 18 & $\underline{2}$ & 7 & $41-44$ \\
\hline rotundicapitata & 850 & 26 & 6 & 8 & 4 & (22 calc) & 14.5 calc & 1.16 & 8 & $\underline{26}$ \\
\hline socialis & $\underline{1,875-3,590}$ & $\underline{42-60}$ & $\underline{6.7-10.6}$ & $\underline{12-21}$ & $3.2-5$ & $\begin{array}{l}4-5.5 \\
\quad(21-33.3)\end{array}$ & $\underline{14-23}$ & $1.1-1.5$ & $5-11$ & $46-96$ \\
\hline tangaroa & $660-817$ & $33-38$ & $6-7$ & $10-12$ & $3-3.8$ & $4(\underline{(29-33)}$ & $11-14$ & 1.18 calc & $\underline{6}$ & $27-34$ \\
\hline taurica & 724-979 & $32-43$ & $\underline{6.7-8.3}$ & $\underline{13-17}$ & $2.5-3.5$ & $\begin{array}{c}3-4(25 \\
\text { calc })\end{array}$ & $13-14$ & 1.36 calc & $?$ & $\underline{23-30}$ \\
\hline uniformis & $\underline{460}$ & $\underline{40}$ & 5 & $\underline{6.7}$ & $\underline{6.5}$ & $(25)$ & $?$ & $\underline{2-2.5}$ & $?$ & $\underline{26}$ \\
\hline vandoverae & $605-760$ & $33-35$ & $6-7$ & $8-10$ & 4 & $\underline{(40)}$ & $12-14$ & $?$ & $\underline{5}$ & $\underline{23-30}$ \\
\hline
\end{tabular}

Character values non-overlapped with those of $H$. hermesi underlined with single line. Double underline means wide hiatus

at a depth of 15-18 $\mathrm{m}$ (Tzetlin et al. 1997; Mokievsky et al. 2005). The accumulation is literally a bar up to $2 \mathrm{~m}$ high, $100 \mathrm{~m}$ long and $25 \mathrm{~m}$ wide. The bar slightly fluctuates in size and delineation from year to year and even within a season. The bulk of detached seeweeds is composed of brown algae Saccharina latissima with addition of Laminaria digitata and Alaria esculenta. Furthermore, some red algae and fucoids are also encountered. Average biomass of the detached macrophytes was estimated as $90 \mathrm{~kg} / \mathrm{m}^{2}$. The accumulation exists since mid-1970s when regular underwater observations began. The accumulation consists of three zones (or layers) with some fuzzy borders between them in the bulk. The upper layer $0.5-1.5 \mathrm{~m}$ wide is formed with fresh and even living fronds, and is well aerated $(\mathrm{Eh}=+45 \mathrm{mV})$. The middle layer of about $20 \mathrm{~cm}$ thick consists of small fragments of algal fronds and is anoxic $(\mathrm{Eh}=-131$ to -345$)$. The small black pieces of algae are densely covered here by cyanobacteria (seventeen species of them were revealed). The lower layer is anoxic (Eh $=-345$ to -360$)$ with a strong smell of hydrogen sulfide. This layer is constituted with black semi-liquid organic matter and remains of kelp stalks. Its thickness was difficult to define, but in all cases, it was more than $0.7 \mathrm{~m}$. Coverage of cyanobacteria is not evident in the lower layer.

\section{Description}

Body elongate spindle-shaped to filiform. Cuticle thin and smooth. Somatic cuticle slightly but distinctly widened at the bend to the apex. 


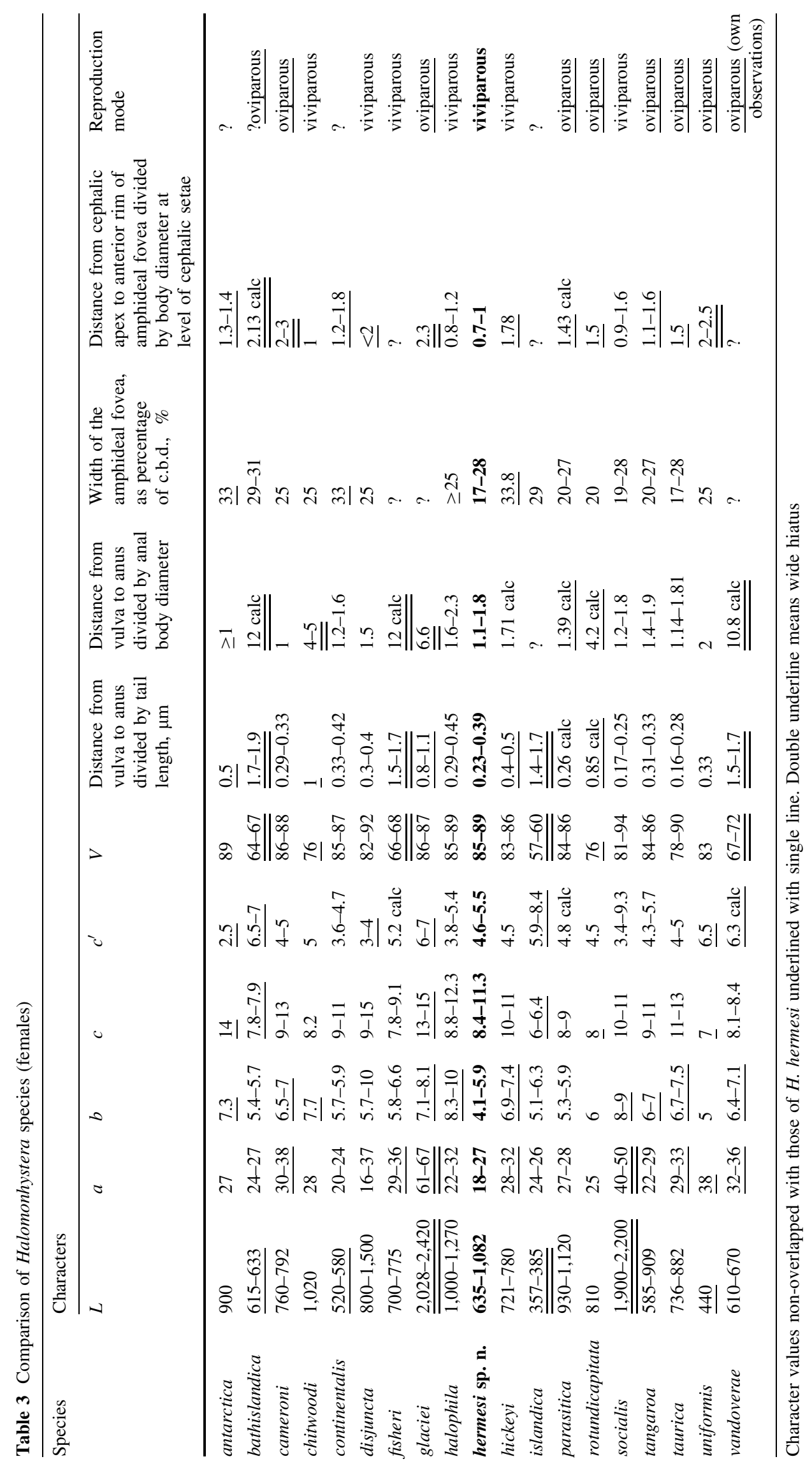


Table 4 Comparison of Halomonhystera hermesi (males) with lineages identified by Fonseca et al. (2008)

\begin{tabular}{|c|c|c|c|c|c|c|c|c|c|}
\hline \multirow{2}{*}{$\begin{array}{l}\text { Species } \\
\text { and } \\
\text { lineages }\end{array}$} & \multicolumn{9}{|l|}{ Characters } \\
\hline & $L$ & $a$ & $b$ & $c$ & $c^{\prime}$ & $\begin{array}{l}\text { Distance from cephalic } \\
\text { apex to anterior rim of } \\
\text { amphideal fovea divided } \\
\text { by body diameter at level } \\
\text { of cephalic setae }\end{array}$ & $\begin{array}{l}\text { Distance from } \\
\text { vulva to anus } \\
\text { divided by } \\
\text { anal body } \\
\text { diameter, } \mu \mathrm{m}\end{array}$ & $\begin{array}{l}\text { Precloacal } \\
\text { supplement }\end{array}$ & $\begin{array}{l}\text { Postcloacal } \\
\text { supplements }\end{array}$ \\
\hline hermesi & $688-1,038$ & 23-29 & $4-6.2$ & $7.9-10.6$ & $3-4.2$ & $0.73-1.4$ & $1.53-1.86$ & present & present \\
\hline GD1 & $969-1,069$ & $27.2-33$ & $3.2-3.9$ & $11.5-13.5$ & $2.8-3.5$ & $0.92-1.06$ & $1.17-1.47$ & present & present \\
\hline GD2 & $953-1,232$ & $29.7-33.9$ & $3.4-4.3$ & $\underline{11.7-13.9}$ & $3.4-3.6$ & $0.86-1.2$ & $1.19-1.57$ & present & present \\
\hline GD3 & $775-1,213$ & $26.7-30$ & 3.3-3.9 & $\underline{11.2-13.5}$ & $3.1-3.4$ & $0.77-0.96$ & $1.4-1.67$ & $\underline{\text { absent }}$ & $\underline{\text { absent }}$ \\
\hline GD4 & $1,034-1,137$ & $28.9-32.3$ & $\underline{3.4-3.6}$ & $\underline{11.1-11.5}$ & $3.4-3.5$ & $0.86-0.93$ & $1.34-1.54$ & present & $?$ \\
\hline GD5 & $873-1,162$ & $25.7-28.5$ & $3.2-3.9$ & $11.7-13.8$ & $3.1-3.5$ & $1.06-1.13$ & $1.66-1.78$ & absent & $?$ \\
\hline
\end{tabular}

Character values non-overlapped with those of $H$. hermesi are underlined with a line

Table 5 Comparison of Halomonhystera hermesi (females) with lineages identified by Fonseca et al. (2008)

\begin{tabular}{|c|c|c|c|c|c|c|c|}
\hline \multirow[t]{2}{*}{ Species and lineages } & \multicolumn{7}{|l|}{ Characters } \\
\hline & $L$ & $a$ & $b$ & $c$ & $c^{\prime}$ & $\begin{array}{l}\text { Distance from cephalic apex } \\
\text { to anterior rim of amphideal } \\
\text { fovea divided by body diameter } \\
\text { at level of cephalic setae }\end{array}$ & $\begin{array}{l}\text { Distance from vulva } \\
\text { to anus divided } \\
\text { by tail length }\end{array}$ \\
\hline hermesi & $635-1,082$ & 17.9-27.2 & $4.1-6$ & $8.4-11.3$ & $4.5-5.5$ & $0.7-1$ & $0.23-0.39$ \\
\hline GD1 & $845-1,125$ & $21-25.3$ & $\underline{2.6-3.8}$ & $9.7-12.7$ & $\underline{3.3-3.8}$ & $\underline{1.22-1.68}$ & $0.19-0.48$ \\
\hline GD2 & $951-1,090$ & $25.5-28.6$ & $\underline{3.0-3.8}$ & $9.8-13.4$ & $4.2-5.3$ & $\underline{1.21-1.46}$ & $0.26-0.49$ \\
\hline GD3 & $911-1,224$ & $21.3-28.1$ & $2.2-3.3$ & $9.3-11.5$ & $4.3-5.4$ & $1.08-1.49$ & $0.29-0.38$ \\
\hline GD4 & $826-1,151$ & $21.1-26.3$ & $\underline{2.8-3.4}$ & $9.6-13$ & $3.5-4.7$ & $1.04-1.69$ & $0.17-0.33$ \\
\hline GD5 & $804-1,005$ & $20.7-23.9$ & $2.1-3.2$ & $\underline{13.1-15.2}$ & $\underline{3.1-3.8}$ & $\underline{1.32-1.92}$ & $0.28-0.38$ \\
\hline
\end{tabular}

Character values non-overlapped with those of $H$. hermesi are underlined with a line

Head region continuous with rest of body. Inner labial papillae minute and hardly visible (Fig. 10b). Outer labial and cephalic sensilla as short cylindrical setae of nearly equal length 1.5-2 $\mu \mathrm{m}$. Outer labial and cephalic setae inserted on two very close but distinctly separated circles $6+4$.

Amphideal fovea small, situated well behind the posterior end of the stoma. Amphideal fovea mostly perfectly round, with distinct cuticular rim. In a few specimens, one of the two foveas, left or right one, may have a posterodorsal interruption of the rim, because of that the fovea looks ventrally coiled in one turn. In males, amphideal fovea $4-5.5 \mu \mathrm{m}$ wide (21-33.33\% c.b.d.), the same in females 4-5 $\mu \mathrm{m}, 19-27.8 \%$ c.b.d., respectively.

A group of short cervical setae (three or two setae in males and one or two setae in females) situated laterally at a distance of one-third of the space between the anterior apex and the nerve ring. Further rearward, one lateral seta may be found at a distance of two thirds of the same space between the anterior apex and the nerve ring in some specimens.

Buccal cavity with thin and weakly sclerotized walls, small and elongate, consisted of short gymnostoma and longer stegostoma surrounded by pharyngeal tissue; no any evident armament or cuticular differentiations. In males, buccal cavity 5-11 $\mu \mathrm{m}$ long and 3-5 $\mu \mathrm{m}$ wide, the same in females 5-9 and 3-6 $\mu \mathrm{m}$, respectively. Pharynx strong, cylindroid, evenly muscular throughout its length, slightly widening to the posterior end. Cardia elongate cardiform, half-surrounded with intestinal tissue.

Body of the ventral gland (renette) cell oval, with light reticulated content and nucleus, situated behind the cardia to the right of the intestine. Ampulla of the ventral gland just posterior to the amphidial fovea. A very thin canal stretched from the ampulla to the labial region, but the outlet of the canal not seen.

Anterior ventricular part of intestine set off by a slight constriction; two anteriormost intestinal cells differentiated from rest of intestine by light-granular content (Fig. 9a).

The single anterior testis situated to the right of the intestine. Spermatocytes arranged in several rows gradually growing in size and acquiring granulation in the cytoplasm (Fig. 9b, c). The spermatozoa (or spermatids?) in vas 
Table 6 Morphometrics of Halomonhystera socialis from the White Sea (detached kelp accumulation)
Measures in $\mu \mathrm{m}$ except for ratios

$a$ body length divided by maximum body diameter; $b$ body length divided by length of the pharynx; $c$ body length divided by tail length; $c^{\prime}$ tail length divided by anal body diameter; $C V$ coefficient of variation; calc ratio calculated from a drawing of original publication; c.b.d.-

corresponding body diameter; $L$ body length, $\mu \mathrm{m} ; n$ number of specimens measured; $S D$ standard deviation; $V$ distance of vulva from anterior end as percentage of body length $(\%)$

\begin{tabular}{|c|c|c|c|c|c|c|c|c|c|c|}
\hline \multirow[t]{2}{*}{ Character } & \multicolumn{5}{|c|}{ Males } & \multicolumn{5}{|c|}{ Females } \\
\hline & $n$ & Min-max & Mean & SD & $\mathrm{CV}$ & $n$ & Min-max & Mean & SD & $\mathrm{CV}$ \\
\hline$L$ & 10 & $1,875-3,590$ & 2,691 & 500 & 18.6 & 16 & $2,499-3,841$ & 3,085 & 382 & 12.4 \\
\hline$a$ & 10 & $42.5-59.8$ & 51 & 5.9 & 11.5 & 16 & $34.2-51.4$ & 44.1 & 5.14 & 11.7 \\
\hline$b$ & 10 & $6.7-10.6$ & 8.8 & 1.34 & 15.3 & 16 & $8.5-13.3$ & 10.4 & 1.57 & 15.2 \\
\hline$c$ & 10 & $12.3-21$ & 16.4 & 2.93 & 17.8 & 16 & $12.2-17.8$ & 14.7 & 1.57 & 10.7 \\
\hline$c^{\prime}$ & 10 & $3.2-5$ & 4.17 & 0.68 & 16.4 & 16 & $3.4-9.3$ & 7.27 & 1.56 & 21.5 \\
\hline$V \%$ & - & - & - & - & - & 16 & $81.3-93.8$ & 88.7 & 2.97 & 3.35 \\
\hline $\begin{array}{l}\text { Distance from vulva } \\
\text { to anus }\end{array}$ & - & - & - & - & - & 17 & $37-48$ & 44.9 & 2.82 & 6.27 \\
\hline $\begin{array}{l}\text { Distance from vulva } \\
\text { to anus divided by } \\
\text { tail length }\end{array}$ & - & - & - & - & - & 15 & $0.17-0.25$ & 0.21 & 0.03 & 13.4 \\
\hline $\begin{array}{l}\text { Distance from vulva } \\
\text { to anus divided by } \\
\text { anal body diameter }\end{array}$ & - & - & - & - & - & 17 & $1.20-1.84$ & 1.61 & 0.20 & 12.7 \\
\hline $\begin{array}{l}\text { Body diameter at } \\
\text { level of cephalic } \\
\text { setae }\end{array}$ & 10 & $11-16$ & 13.5 & 1.72 & 12.7 & 17 & $11-15$ & 13.5 & 1.23 & 9.14 \\
\hline $\begin{array}{l}\text { Body diameter at } \\
\text { level of amphideal } \\
\text { foveas }\end{array}$ & 10 & $15-23$ & 19.1 & 2.28 & 12 & 17 & $18-24$ & 20.4 & 1.58 & 7.76 \\
\hline $\begin{array}{l}\text { Body diameter at } \\
\text { level of nerve ring }\end{array}$ & 10 & $28-45$ & 31.6 & 8.82 & 16 & 17 & $28-42$ & 34.5 & 3.97 & 11.5 \\
\hline $\begin{array}{l}\text { Body diameter at } \\
\text { level of cardia }\end{array}$ & 10 & $32-51$ & 39.9 & 5.45 & 13.6 & 17 & $37-50$ & 42.6 & 3.86 & 9.06 \\
\hline Midbody diameter & 10 & $39-63$ & 52.8 & 8.72 & 16.5 & 17 & $60-80$ & 69.2 & 6.05 & 8.75 \\
\hline Anal body diameter & 10 & $33-45$ & 39.7 & 4.35 & 10.9 & 17 & $25-38$ & 28.3 & 3.51 & 12.4 \\
\hline $\begin{array}{l}\text { Distance from } \\
\text { cephalic apex to } \\
\text { anterior rim of } \\
\text { amphideal fovea }\end{array}$ & 10 & $14-23$ & 17.2 & 2.82 & 16.4 & 17 & $13-23$ & 17.2 & 2.74 & 16.0 \\
\hline $\begin{array}{l}\text { Distance from } \\
\text { cephalic apex to } \\
\text { anterior rim of } \\
\text { amphideal fovea } \\
\text { divided by body } \\
\text { diameter at level of } \\
\text { cephalic setae }\end{array}$ & 17 & $1.13-1.44$ & 1.27 & 0.1 & 7.58 & 17 & $0.93-1.57$ & 1.27 & 0.16 & 12.2 \\
\hline $\begin{array}{l}\text { Spicule's length along } \\
\text { chord }\end{array}$ & 10 & $45.9-80$ & 54.4 & 11.24 & 20.7 & - & - & - & - & - \\
\hline $\begin{array}{l}\text { Spicule's length along } \\
\text { arch }\end{array}$ & 10 & $45.9-96$ & 71.5 & 15.3 & 21.4 & - & - & - & - & - \\
\hline $\begin{array}{l}\text { Length of apophysis } \\
\text { of gubernaculum }\end{array}$ & 9 & $3-6$ & 4.89 & 1.05 & 21.6 & - & - & - & - & - \\
\hline
\end{tabular}

deferens oval-shaped with homogeneous content. The later spermatids (or spermatozoa) rather large cells of ovoid or pear-like shape with inner vermiculation (Fig. 9d). Walls of the vas deferens thick, with fine longitudinal fibrosity. In the middle part, the vas deferens covered laterally with three to four large spindle-shaped cells with nuclei and light reticulated cytoplasm. Further posteriad, a short part of the vas deferens is made up of large cells with light reticulated content (Fig. 9e). Even more posteriad, cells of the vas deferens become smaller and with coarser internal granulation. On both sides, eleven to twelve ejaculatory gland cell bodies along posterior part of the vas deferens at each lateral side (Figs. 8a, b, 9f). Spicules slender and arcuate, proximally (anteriorly) with small, slightly asymmetrical knobs and distally (posteriorly) pointed. Gubernaculum with a small dorso-caudal apophysis as an unpaired triangular projection. A small midventral preanal papilla just anterior to the cloacal opening (Fig. 10c). 
Fig. 6 Halomonhystera socialis, entire views and posterior bodies. a Entire male; b entire female; $\mathbf{c}$ male posterior body showing copulatory apparatus; $\mathbf{d}$ female posterior body. Scale bars a, b $500 \mu \mathrm{m}$; c, d $50 \mu \mathrm{m}$
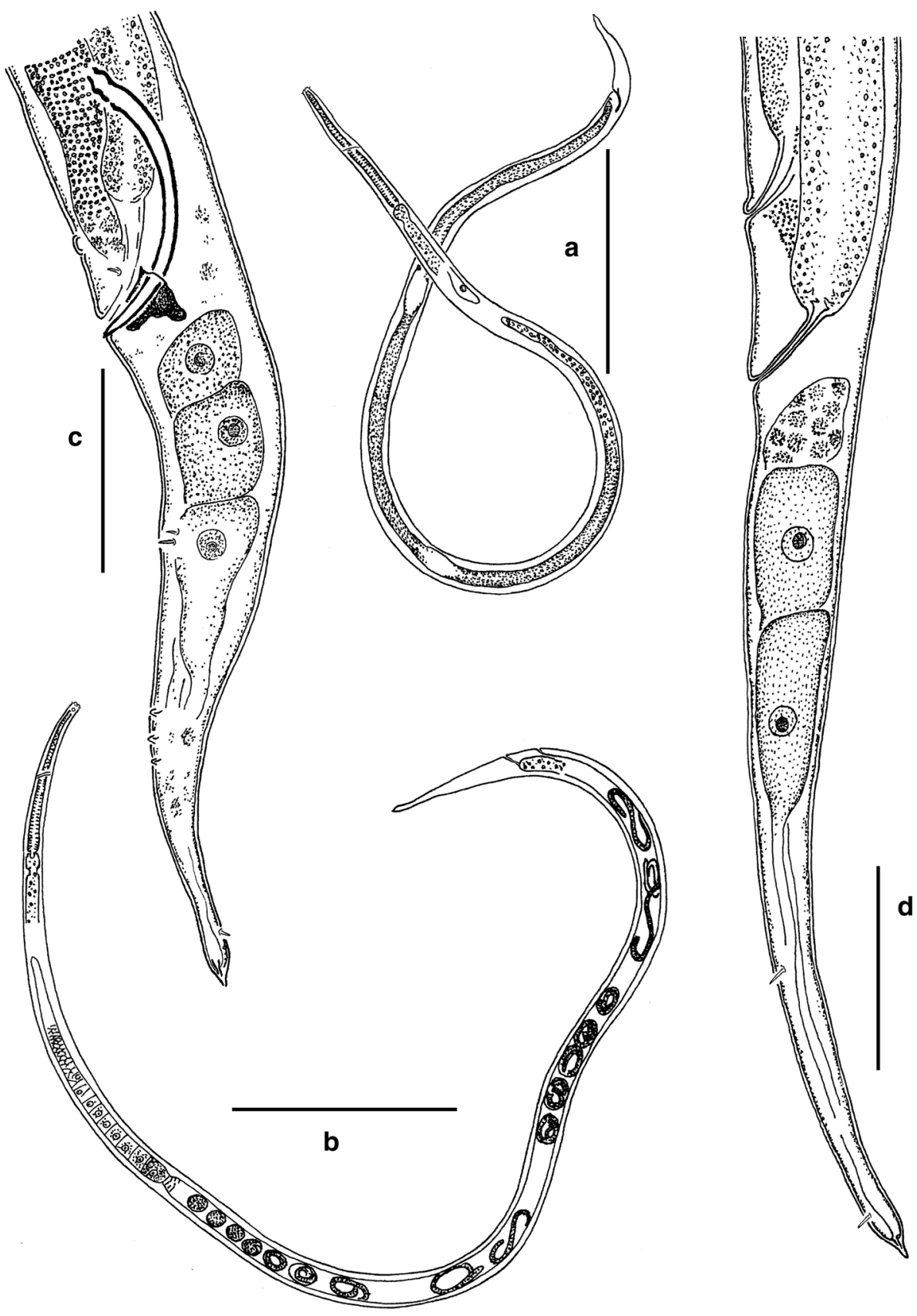

Single female genital branch very long and situated entirely to the right of the intestine (Fig. 10d). Uterus long and spacious, and containing cleaving ova at successive stages of development up to 55 in number, and also up to 23 first stage juveniles hatched in uterus (Fig. 10e, f).

Tail elongate-conical. Two or three incaudal gland cell bodies visible clearly within the tail of females visible and less distinct within the tails of males. Terminal cone with an internal curved cuticular funnel within the spinneret (Fig. 7d).

A few irregular lateral and latero-ventral pairs of short setae on the preanal region and on the tail. Male with one sometimes indistinct midventral preanal papilla (Fig. 10c). Male tail with three successive pairs of subventral conical papillae close to one another on the posterior half of the tail.

\section{Diagnosis}

Halomonhystera. Body length $1,875-3,841 \mu \mathrm{m}$, body length divided by maximum body diameter $34-60$, body length divided by length of the pharynx $6.7-13.3$, body length divided by tail length 12.2-21, tail length divided by anal body diameter 3.2-5 in males and 3.4-9.3 in females, distance of vulva from anterior end as percentage of body 
Fig. 7 Halomonhystera socialis, body ends. a Male head region sublateral view; b male head region, lateral view; c female head region, midventral view; $\mathbf{d}$ tail end of a male. Scale bars $10 \mu \mathrm{m}$
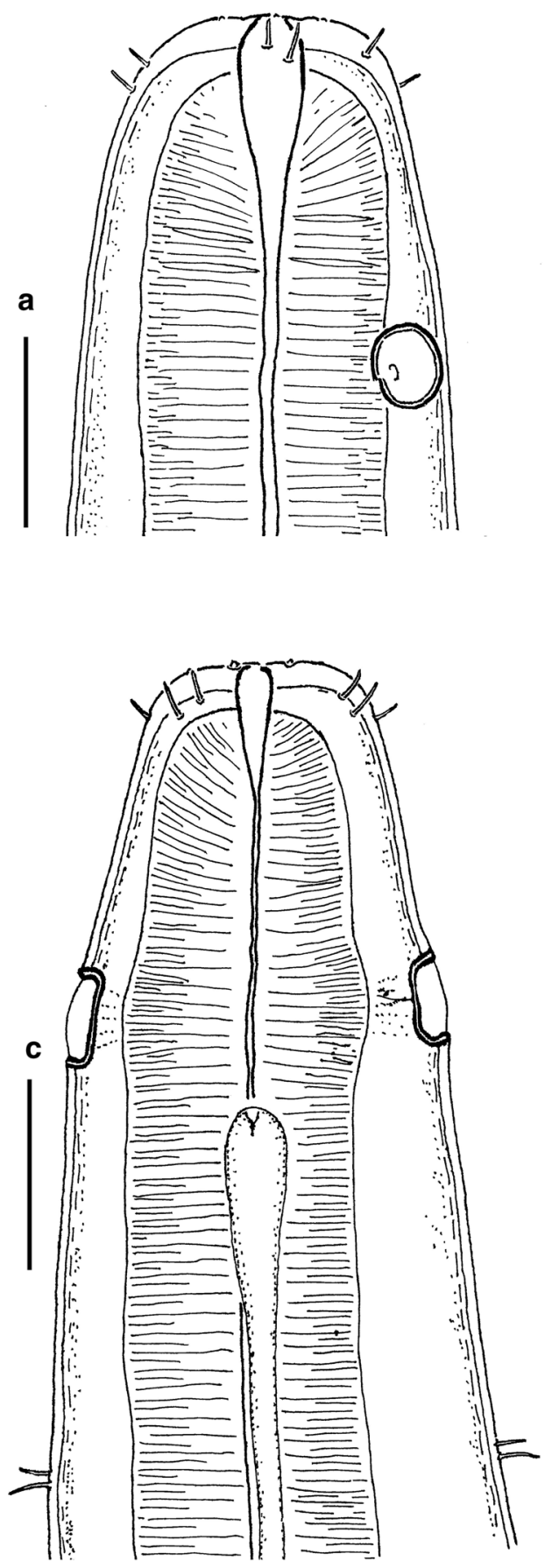
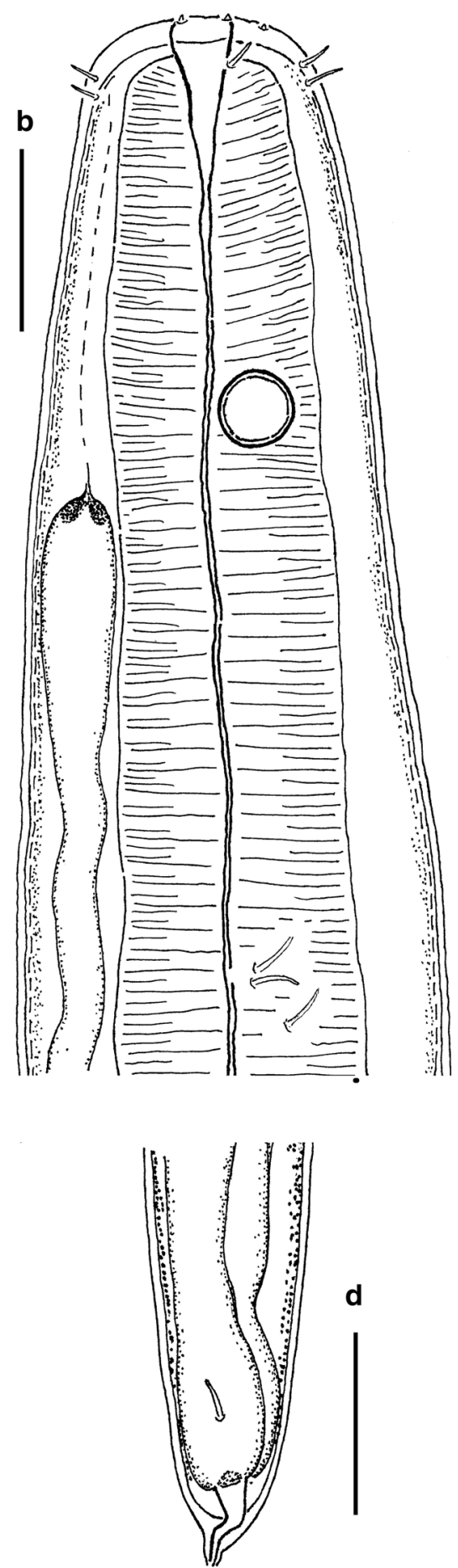

length 81.3-93.8 \%, tail length divided by distance vulvaanus 4-6. Body elongate spindle-shaped to filiform. Amphideal fovea 21-33\% of corresponding body diameter in males and 19-28\% in females, at a distance 13-23 $\mu \mathrm{m}$ from the cephalic apex. Two to three lateral setae postamphideal setae present. Pharyngostoma conical, with weakly sclerotized walls. Viviparous. Male with a small midventral preanal papilla and three successive separated pairs of minute subventral papillae on posterior half of the tail. Spicules 46-96 $\mu \mathrm{m}$ (arch). Gubernaculum with short dorso-caudal apophysis.

\section{Remarks}

Original description of $H$. socialis was performed largely on a female; the male was mentioned but not measured, 
Fig. 8 Halomonhystera socialis, male posterior structures. a Posterior body region; b pericloacal region. Scale bars a $50 \mu \mathrm{m}, \mathbf{b} 10 \mu \mathrm{m}$

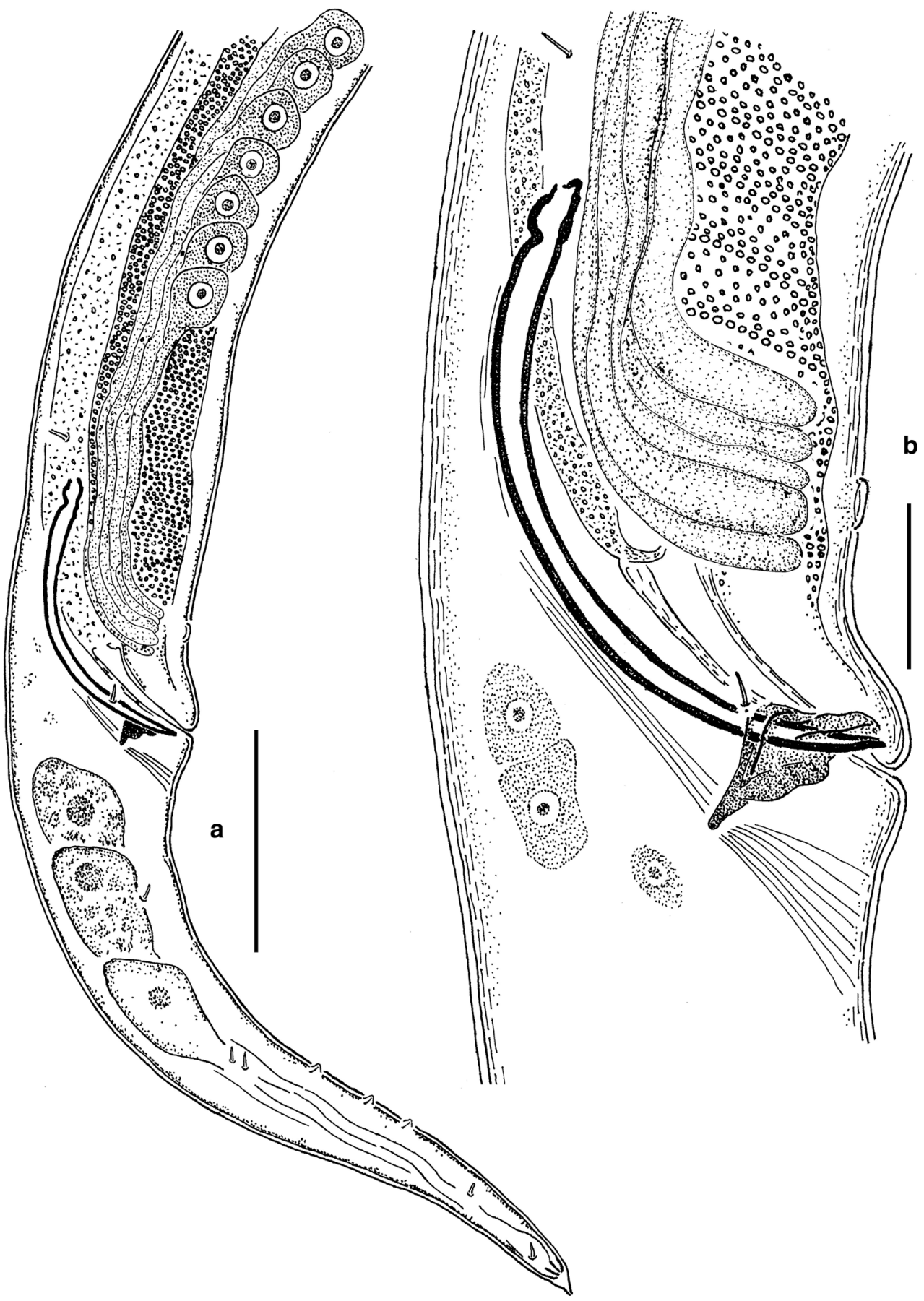

and for male, only tail and spicules were illustrated (Bütschli 1874). Subsequent redescriptions and mentions are mostly brief and add little to the differentiation of the species. The most evident feature permitting to discriminate this species from the others is the significantly larger body size as was also noted by Steiner (1958).

Our specimens fit well in all dimensional characters to H. socialis and differ sharply from all the other Halomonhystera species thus far described. H. socialis had been described from decaying algae in the Kiel Bight, a habitat that could be analogous to that of the White Sea.

Molecular data

Two out of 20 White Sea (WS) H. socialis specimens yielded two additional cytochrome oxidase subunit I (COI) haplotypes compared to previously known deep-sea Håkon Mosby mud volcano (HMMV, H. hermesi) and intertidal 

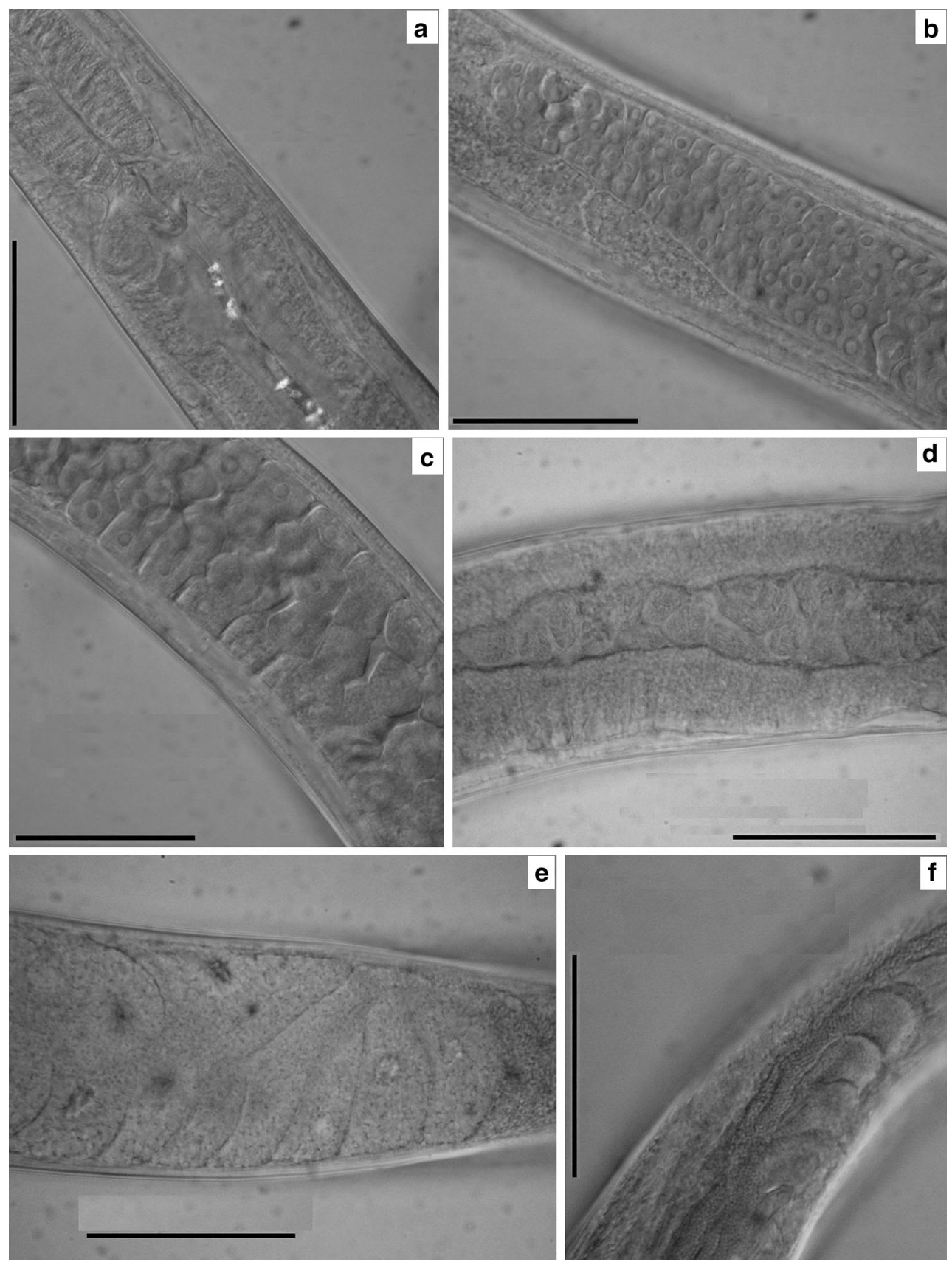

Fig. 9 Halomonhystera socialis, male details. a Posterior pharynx, cardia and ventricular region of intestine; $\mathbf{b}$ anterior tip of testis, spermatogonia; c posterior part of testis, spermatocytes; d vas

(GD-5) haplotypes. The COI alignment was $343 \mathrm{bp}$ long and contained 153 variable sites of which 125 were parsimony informative. The phylogenetic trees revealed six highly distinct clades (Fig. 11). Interestingly, the newly retrieved $H$. socialis COI sequences belonged to the deepsea HMMV $H$. hermesi clade and will further be referred to as the H. hermesi-H. socialis clade. The presence of GD4 haplotype G16 resulted in a maximum interspecific uncorrected p-distance of $10.9 \%$ within the GD4 lineages. deferens, spermatids in the lumen; e vas deferens, zone of light wall cells; f ejaculatory gland cell bodies. Scale bars $50 \mu \mathrm{m}$

Removing haplotype G16 from the dataset revealed that divergence ranges were much lower within the six observed lineages (0.3-2.9\%) than between lineages (13.3-26.4\%, Table 7).

To investigate the observed clades further, we have sequenced the first $900 \mathrm{bp}$ of the $18 \mathrm{~S}$ sequence for three WS $H$. socialis specimens and added those to publically available HMMV $H$. hermesi (Van Campenhout et al. 2014) and intertidal (GD1-5) sequences (Derycke et al. 

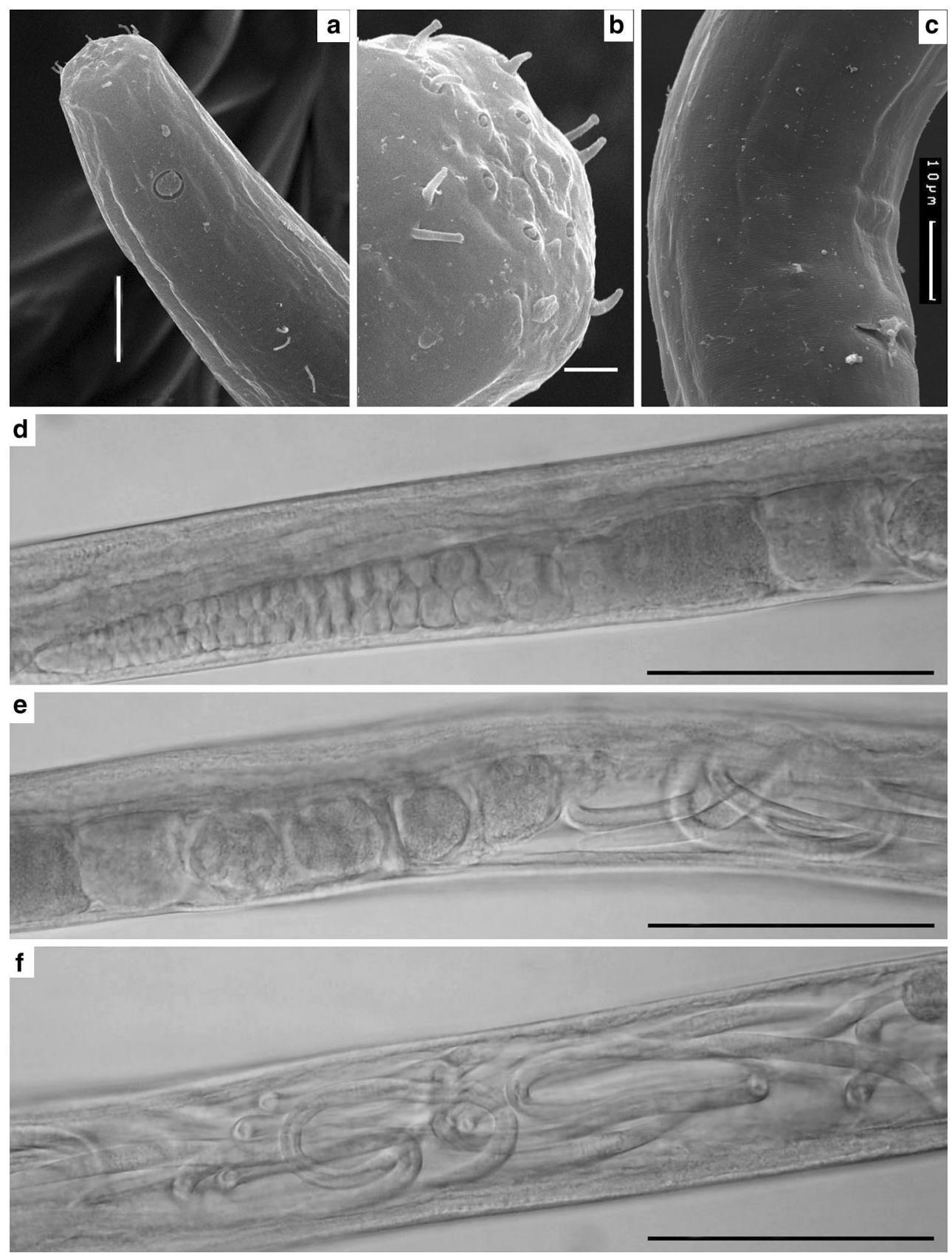

Fig. 10 Halomonhystera socialis, structures of males and females. a Female head laterally (SEM); b female labial region (SEM); c male precloacal area (SEM); d female ovary; e anterior female uterus with

2007). After applying G-blocks, the alignment was 723 bp long and contained 166 variable sites of which 164 were parsimony informative. The phylogenetic tree now only revealed four clades, GD2/5, GD3, HMMV H. hermesi and GD1/4/WS $H$. socialis (Fig. 12). WS $H$. socialis specimens were now positioned together with GD1 and GD4 specimens with strong support (bootstrap values for ML, MP, NJ and BA were 97, 99, 95 and 89, respectively). The position of the GD3 and $H$. hermesi clade remained ambiguous. embryos and juveniles; f posterior female uterus with free juveniles. Scale bars a $10 \mu \mathrm{m} ; \mathbf{b} 2 \mu \mathrm{m}$; c $10 \mu \mathrm{m}$; d-f $100 \mu \mathrm{m}$

Due to very low uncorrected p-distances as a result of highly similar sequences between GD2 and GD5, and between GD1, GD4 and WS $H$. socialis specimens (Table 8), we ended up with a phylogenetic tree with a low resolution within two clades.

To explore these clades into more detail, two additional nuclear genes (ITS and D2D3) were sequenced for four WS $H$. socialis specimens and subsequently added to published HMMV and intertidal nematodes. After concatenation of 
Fig. 11 Maximum likelihood of a heuristic analysis of the mitochondrial cytochrome oxidase c subiunit I (COI) gene of intertidal- $[\mathrm{H}$. disjuncta $1-5$ (GD1-5)], deep-sea (HDHMMV, H. hermesi) and White Sea (WS, H. socialis) nematodes. Bootstrap values correspond to maximum likelihood, maximum parsimony, neighbor-joining and Bayesian analysis. A slash indicates the absence of a branch in the respective analysis. The outgroup AM748759.1 is D. meyli

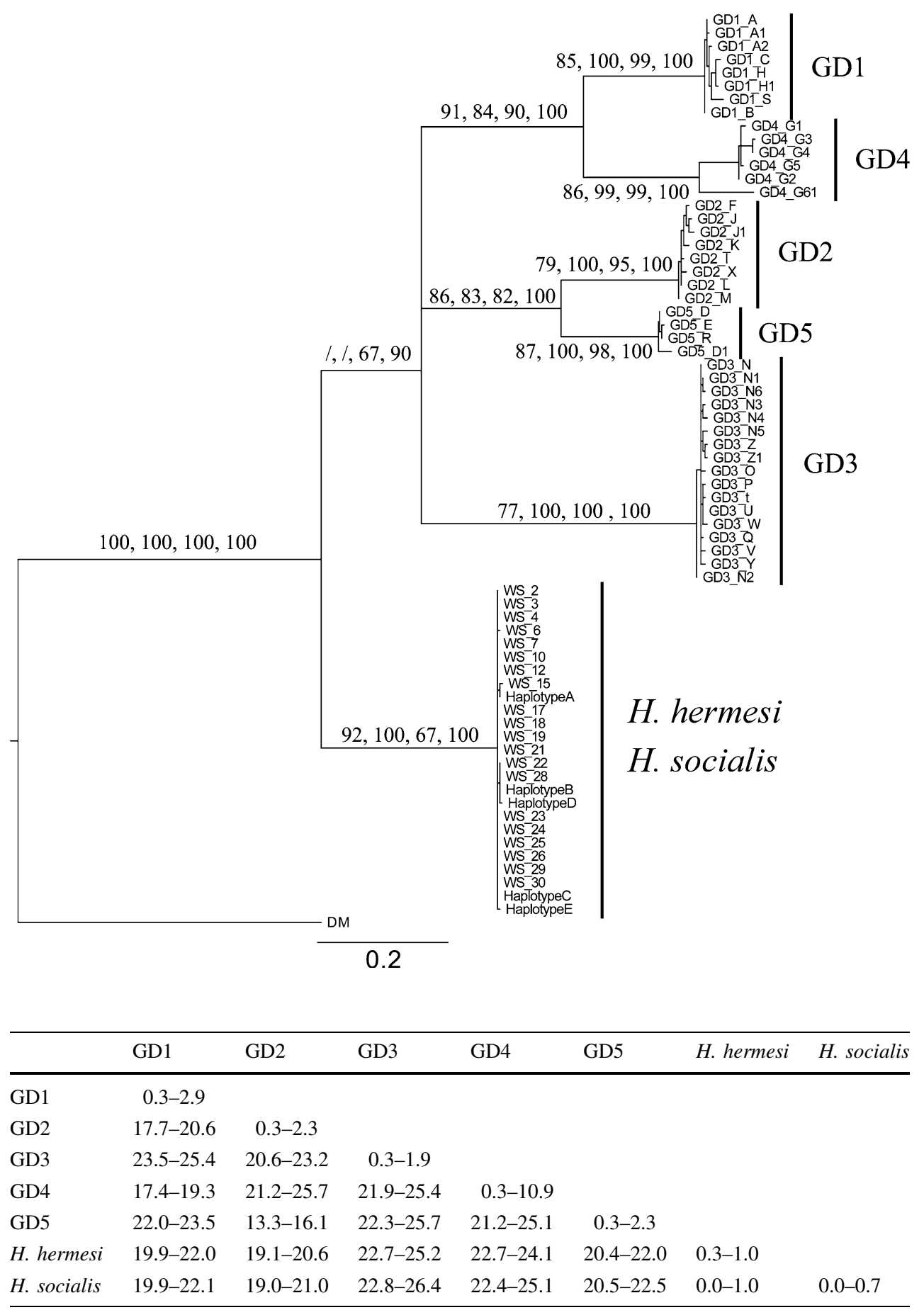

Table 7 Minimum and maximum uncorrected p-distances (\%) of cytochrome oxidase c subunit I (COI) between intertidal $H$. disjuncta 1-5 (GD1-5), Halomonhystera hermesi and White Sea Halomonhystera socialis agreement with the $18 \mathrm{~S}$ phylogenetic tree, the WS $H$. socialis specimens are again positioned close to GD1 and GD4 with high support (bootstrap values for ML, MP, NJ and BA were 99, 100, 100 and 100, respectively). Furthermore, the position of the $H$. hermesi clade was now resolved and showed a highly supported phylogenetic relationship with the GD1/4/WS $H$. socialis (bootstrap values for ML, MP, NJ and BA were 97, 99, 88 and 100, (Fig. 13). However, the WS, GD1 and GD4 clades were 
Fig. 12 Maximum likelihood tree of a heuristic analysis of the 18S $\mathrm{r}$ DNA of intertidal $H$. disjuncta 1-5 (GD1-5), deepsea HMMV $H$. hermesi and White Sea $H$. socialis. Bootstrap values above each branch correspond to maximum likelihood, maximum parsimony, neighbor-joining and Bayesian analysis. A slash indicates the absence of a branch in the respective analysis. Trees are mid-point rooted

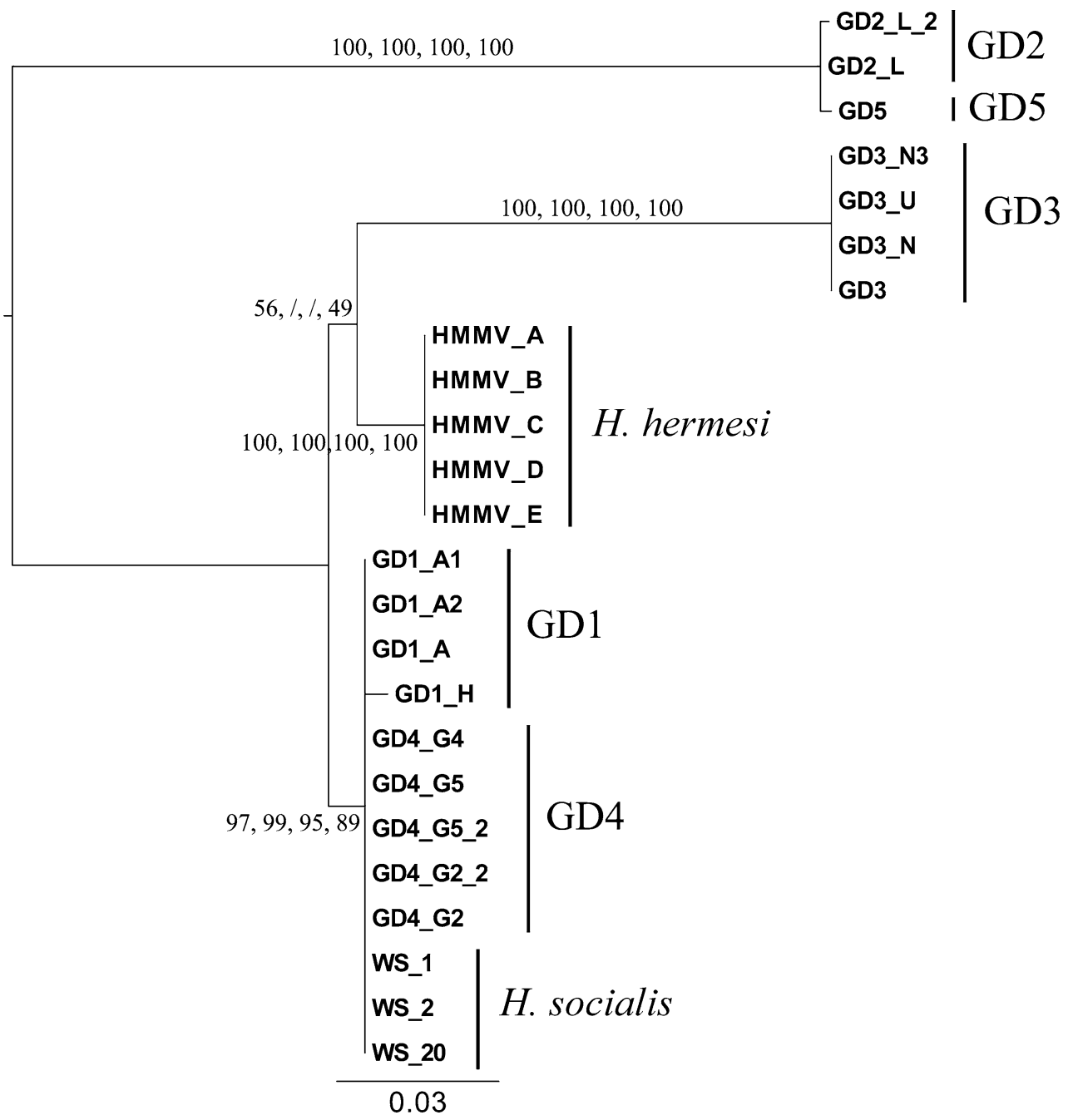

\begin{tabular}{llllllll}
\hline & GD1 & GD2 & GD3 & GD4 & GD5 & H. hermesi & H. socialis \\
\hline GD1 & $0.0-0.4^{*}$ & $15.7-16.7$ & $8.7-9.0$ & $0.0-0.4$ & $18.8-19.2$ & $2.4-2.8$ & $0.0-0.4$ \\
& $0.1-0.1^{* *}$ & & & & & & \\
GD2 & $12.4-14.0$ & $0.2-0.2^{*}$ & $18.4-19.5$ & $15.7-16.4$ & $0.2-0.2$ & $16.3-16.9$ & $15.7-16.6$ \\
& & $0.2-0.2^{* *}$ & & & & & \\
GD3 & $12.4-14.0$ & $16.0-16.8$ & $0.0-0.0^{*}$ & $8.7-8.8$ & $22.5-23.0$ & $8.9-8.9$ & $8.4-8.5$ \\
& & & $1.5-1.5^{* *}$ & & & & \\
GD4 & $0.5-0.7$ & $14.0-14.1$ & $13.0-13.9$ & $0.0-0.0^{*}$ & $18.8-18.8$ & $2.4-2.4$ & $0.0-0.0$ \\
& & & & $0.0-0.2^{* *}$ & & & \\
GD5 & $12.3-14.3$ & $2.2-2.3$ & $16.5-17.1$ & $14.3-14.4$ & $0.0-0.0^{*}$ & $19.4-19.4$ & $18.8-18.8$ \\
& & & & & $0.1-0.1 * *$ & & \\
H. hermesi & $8.6-9.0$ & $13.9-14.0$ & $13.6-14.3$ & $8.5-8.7$ & $13.6-13.6$ & $0.0-0.0^{*}$ & $1.9-1.9$ \\
& & & & & & $0.0-0.0^{* *}$ & \\
H. socialis & $0.4-0.6$ & $14.1-14.3$ & $13.3-14.1$ & $0.6-0.8$ & $14.3-14.5$ & $8.4-8.5$ & $0.0-0.0^{*}$ \\
& & & & & & & $0.0-0.0^{* *}$ \\
\hline
\end{tabular}


Fig. 13 Maximum likelihood tree of a heuristic analysis of the concatenated nuclear genes internal transcribed spacer region and $D 2 D 3$ region of $28 S$ $r D N A(\mathrm{~B})$ of intertidal- $(H$. disjuncta 1-5 (GD1-5)), deepsea-(HMMV H. hermesi) and White Sea (WS H. socialis) nematodes. Bootstrap values above each branch correspond to maximum likelihood, maximum parsimony, neighborjoining and Bayesian analysis. A slash indicates the absence of a branch in the respective analysis. Trees are mid-point rooted

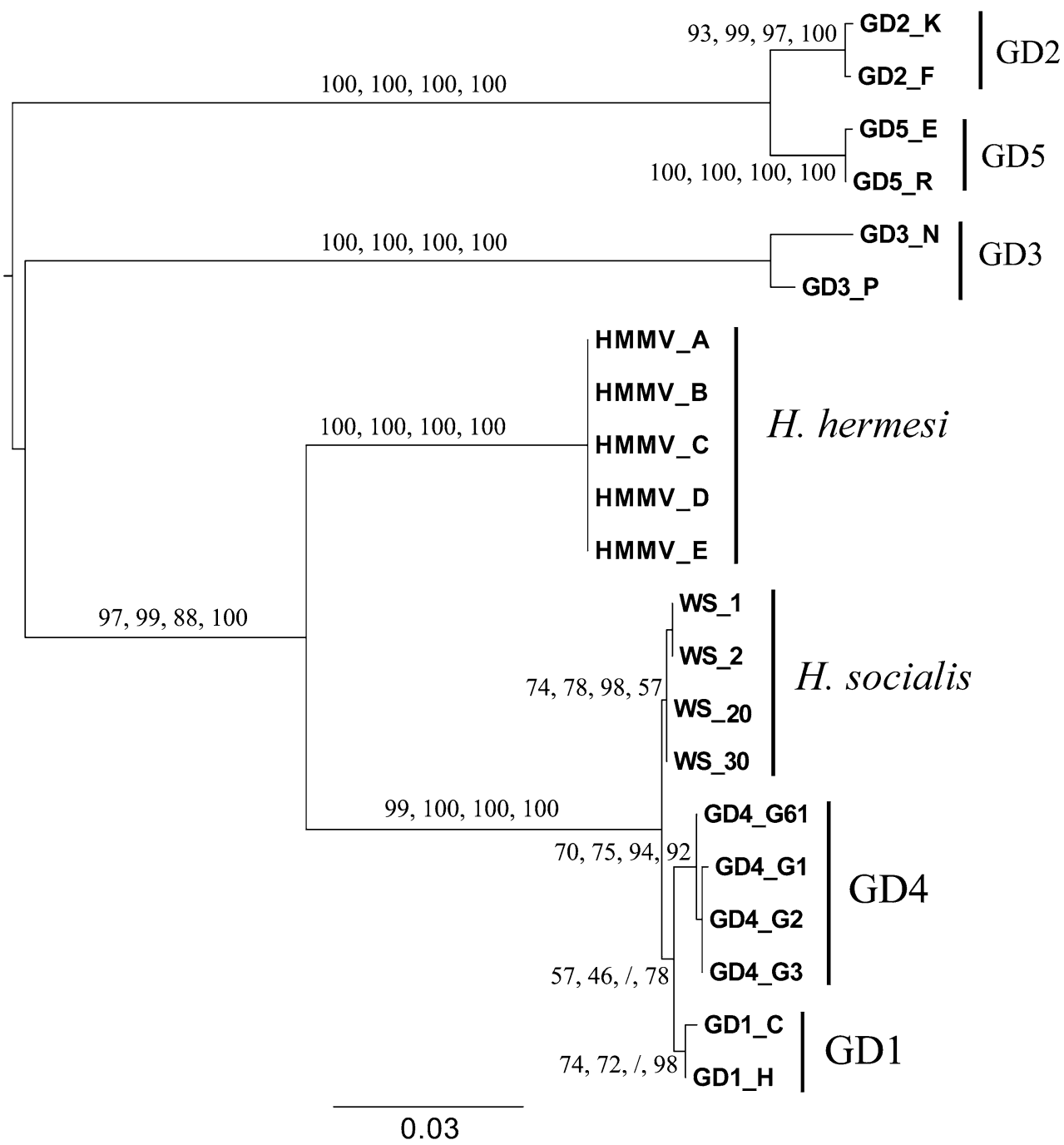

respectively). Interspecific divergences between species range from 0.0 to $23.0 \%$ and from 0.4 to $17.1 \%$ for $18 \mathrm{~S}$ and the concatenated ITS-D2D3 sequence, rerspectively.

\section{Discussion}

Our data show that Håkon Mosby mud volcano (HMMV) and White Sea (WS) nematodes are an integral part of the intertidal (GD1-5) cryptic species complex. HMMV nematodes from the deep sea were morphologically and genetically different from the intertidal species (GD1-5; Van Campenhout et al. 2014). In both the nuclear and mitochondrial phylogenetic tree, the HMMV nematodes consisted of a separated clade in relation to the intertidal species (GD1-5). Consequently, the HMMV nematodes were considered as a new species (Van Campenhout et al. 2014) and are described here as $H$. hermesi sp. n. Including WS specimens, identified here morphologically and morphometrically as $H$. socialis Bütschli (1874) revealed that the genetic distance, based on mitochondrial data, between $H$. socialis and $H$. hermesi was very low $(0.0-1.0 \%)$ and in the range of intraspecific variability observed for this gene (Derycke et al. 2010b). Mitochondrial sequences of both species were, however, different from the five intertidal species, with minimum genetic divergences between the HMMV-WS clade and intertidal clades (GD1-5) exceeding the $5 \%$ threshold level proposed for marine nematodes.

Using a single-gene library (DNA barcoding), e.g., COI sequences, to identify species has gained increasing interest in the last decade (Blaxter 2004; Hebert et al. 2003a, 2003b). Even though the use of COI in identifying marine nematode species showed great promise (Derycke et al. 2010b), the morphological different species Paracanthonchus/Praeacanthonchus did not reveal to have distinct COI sequences, which is similar to our study (H. socialis versus $H$. hermesi specimens). DNA barcoding methods return the 
species identification problem back to a single-charactersystem approach (though each nucleotide may be considered a character), which puts new constraints on species identification of morphologically different species exhibiting the same barcoding sequence (Will et al. 2005). Similar COI sequences in morphological different species might be the result of stabilizing selection (Hablutzel et al. 2013). However, we are currently unable to identify which (a)biotic factors would play a role. Second, there is the possibility of polyphyly or incomplete lineage sorting (Funk and Omland 2003), which could complicate the correct delineation of species. Third, introgression between $H$. socialis and $H$. hermesi could blur deeper phylogenetic relations (Chase et al. 2005). However, $H$. socialis and $H$. hermesi are geographically and bathymetrically separated by about 1,000 sea miles (around Scandinavia and Kola Peninsula) and $>1,000 \mathrm{~m}$, respectively. Introgression between both species is therefore unlikely to have generated the similar COI sequences.

Even though we are currently in the dark considering the reason why similar COI sequences between $H$. socialis and $H$. hermesi nematodes were observed, both species showed a larger genetic divergence based on nuclear sequences. Our nuclear data show that the genetic divergence between $H$. socialis and $H$. hermesi nematodes was very low for the D2D3 region (1.0-1.0 \%) and the $18 \mathrm{~S}(1.9-1.9 \%)$, while the genetic divergence for the ITS region ranged between 12.2 and $12.3 \%$. In addition to a barcoding approach based on COI data, the D2D3 region of the 28S rDNA has been suggested as an alternative approach (Pereira et al. 2010). However, our results reveal that $H$. socialis specimens have the same sequence as GD1 and GD4 implying that using molecular data is insufficient for correct species identification. Using barcoding based on a single-gene approach might show great promises for species identification, and using such an approach is insufficient for correct delineation of species. Therefore, other types of data should be taken into account. It has been suggested that an integrative approach is the most solid method for adequate species delineating (Bhadury and Annapuma 2011; Puillandre et al. 2012; Will et al. 2005). Such an integrative approach uses, in addition to molecular data, other types of data like morphology, geographical distribution, reproduction isolation, etc.

The $H$. disjuncta complex includes those species of the genus Halomonhystera, which has vulva situated very close to the anal opening. Level of structural differentiation between species of $H$. disjuncta complex is, however, very low. All the characters usually used for intrageneric species discrimination in aquatic nematodes such as position of amphideal fovea, shape and size of buccal cavity, spicules and gubernaculum, pericloacal specialized sensory organs do not work well in the case of $H$. disjuncta complex. All the species have these structures located in similar positions such as lateral cervical setae posterior to the amphids, midventral preanal papilla and pairs of subventral papillae on the male tail. Morphospecies established on the base of morphological characters actually differ from one another on the ground of body size and ratios and some finer morphometric parameters. Some species such as $H$. socialis are characterized by apparent size chiatus while other species are not. The complex consists of cryptospecies, semicryptospecies and species relatively easier recognizable on the base of morphometrics. Anyway, it becomes evident the species of $H$. disjuncta complex can be identified by only using both molecular and morphometric methods.

Taking all the findings: nuclear sequence divergence (especially between White Sea and Håkon Mosby mud volcano nematodes), mitochondrial sequence divergences (between intertidal and the WS-HMMV clade), geographical separation and morphological/morphometric differences between all cryptic species, into account, we conclude that both WS and HMMV should be considered as two different species. The HMMV species is morphologically distinct from other GD1-5 species as well as from known morphospecies of the $H$. disjuncta complex and is described here as a formal new species $H$. hermesi sp. n. The WS species being also distinct from other GD1-5 species also differs from all morphospecies of the $H$. disjuncta complex except $H$. socialis (Bütschli 1874) by its much greater body size. WS species fits in morphometrics to this distinct but poorly known species. Our results confirm that an integrative approach (molecular and morphology) is the most solid method for a correct identification of nematodes (De Ley and Blaxter 2002; Derycke et al. 2010a; Holterman et al. 2006; Meldal et al. 2007) and is highly recommended for the discrimination between WS and HMMV nematodes.

Acknowledgments The authors thanks both anonymous reviewers for valuable remarks which could help to improve the manuscript. Research was supported by the grant of the Council of President of Russian Federation NSH-1801.2014.4.

\section{References}

Allgén C (1935) Die freilebende Nematoden des Öresunds. Capita Zool 6(3):1-192

Andrássy I (1981) Revision of the order Monhysterida (Nematoda) inhabiting soil and inland waters. Opusc zool Bpest 17-18:13-47

Andrássy I (2006) Halomonhystera, a new genus distinct from Geomonhystera Andrássy, 1981 (Nematoda: Monhysterida). Meiofauna Mar 15:11-24

Bastian HC (1865) Monograph on the Anguillulidae, or free Nematoids, marine, land, and freshwater; with descriptions of 100 new species. Trans Linn Soc Lond 25:73-184

Bhadury P, Annapuma C (2011) Marine barcoding-how will it help Indian marine benthic studies? Indian J Geo Mar Sci 40:645-647 
Bhadury P, Austen MC, Bilton DT, Lambshead PJD, Rogers AD, Smerdon GR (2006) Development and evaluation of a DNAbarcoding approach for the rapid identification of nematodes. Mar Ecol Prog Ser 320:1-9

Bhadury P, Austen MC, Bilton DT, Lambshead PJD, Rogers AD, Smerdon GR (2008) Evaluation of combined morphological and molecular techniques for marine nematode (Terschellingia sp.) identification. Mar Biol 154:509-518

Blaxter ML (2004) The promise of a DNA taxonomy. Philos Trans R Soc Lond Ser B Biol Sci 359:669-679

Blome D, Riemann F (1999) Antarctic sea ice nematodes, with description of Geomonhystera glaciei sp. n. (Monhysteridae). Mitt Zool Mus Inst Hamburg 96:15-20

Bresslau E, Stekhoven JHS (1940) Marine freilebende Nematoden aus der Nordsee. Musée Hist Nat Brux 1940:1-74

Bütschli O (1874) Zur Kenntnis der freilebenden Nematoden, insbesondere der des Kieler Hafens. Abh Senckenb Naturforsch Ges 9:236-292

Castresana J (2000) Selection of conserved blocks from multiple alignments for their use in phylogenetic analysis. Mol Biol Evol 17:540-552

Chase MW, Salamin N, Wilkinson M, Dunwell JM, Kesanakurthi RP, Haidar N, Savolaine V (2005) Land plants and DNA barcodes: short-term and long-term goals. Philos Trans R Soc B Biol Sci 360:1889-1895

Chitwood BG (1951) North American marine nematodes. Tex J Sci 3:617-672

Chitwood BG, Murphy DG (1964) Observations on two marine monhysterids - their classification, culture and behavior. Trans Am Microsc Soc 83:311-329

Cobb NA (1914) Antarctic marine free-living nematodes of the Shakleton Expedition. Contrib Sci Nematol (Baltim) 1:1-33

Cobb NA (1918) Filter-bed nemas: nematodes of the slow sand filterbeds of American cities. Contrib Sci Nematol (Baltim) 7:189-212

De Coninck LA (1943) Sur quelques espèces nouvelles de Nématodes libres de des eaux et des terres saumâtres de 1 'Islande. Biol Jaarb Dodonaea 10:193-219

De Coninck LA, Stekhoven JHS (1933) The free-living marine nemas of the Belgian coast II. Mém Mus $r$ d'Hist nat Belg 58:1-163

De Ley P, Blaxter ML (2002) Systematic position and phylogeny. In: Lee DL (ed) The biology of nematodes. Taylor and Francis, London, pp 1-30

De Ley P, De Ley IT, Morris K, Abebe E, Mundo-Ocampo M, Yoder M, Heras J, Waumann D, Rocha-Olivares A, Burr AHJ, Baldwin JG, Thomas WK (2005) An integrated approach to fast and informative morphological vouchering of nematodes for applications in molecular barcoding. Philos Trans R Soc B Diol Sci 360:1945-1958

De Man JG (1888) Sur quelques Nématodes libres de la mer du Nord nouveaux ou peu connu. Mém Soc Zool Fr 1:1-51

Derycke S, Remerie T, Vierstraete A, Backeljau T, Vanfletern J, Vincx M, Moens T (2005) Mitochondrial DNA variation and cryptic speciation within the free-living marine Pellioditis marina. Mar Ecol Prog Ser 300:91-103

Derycke S, Backeljau T, Vlaeminck C, Vierstraete A, Vanfletern J, Vincx M, Moens T (2007) Spatiotemporal analysis of population genetic structure in Geomonhystera disjuncta (Nematoda, Monhysteridae) reveals high levels of molecular diversity. Mar Biol 151:1799-1812

Derycke S, De Ley P, De Ley IN, Holovachov O, Rigaux A, Moens T (2010a) Linking DNA sequences to morphology: cryptic diversity and population genetic structure in the marine nematode Thoracostoma trachygaster (Nematoda, Leptosomatidae). Zool Scr 39(3):276-289
Derycke S, Vanaverbeke J, Rigaux A, Backeljau T, Moens T (2010b) Exploring the use of cytochrome oxidase c subunit 1 (COI) for DNA barcoding of free-living marine nematodes. PLoS One 5:e13716

Filipjev IN (1922) Encore sur les Nématodes de la Mer Noire. Trudy stavropolskogo selskokhozjaistvennogo instituta 1:83-184

Floyd R, Abebe E, Papert A, Blaxter M (2002) Molecular barcodes for soil nematode identification. Mol Ecol 11:839-850

Fonseca G, Decraemer W (2008) State of the art of the free-living marine Monhysteridae (Nematoda). J Mar Ass UK 88(7):1371-1390

Fonseca G, Derycke S, Moens T (2008) Integrative taxonomy in two free-living nematode species complexes. Biol J Linn Soc 94:737-753

Funk DJ, Omland KE (2003) Species-level paraphyly and polyphyly: frequency, causes, and consequences, with insights from animal mitochondrial DNA. Ann Rev Ecol Evol Syst 34:397-423

Geraert E, Reuse Ch, Van Brussel D, Vranken G (1981) The female reproductive system in Monhystera (Nematoda: Monhysterida). Biol Jaarb Dodonaea 49:148-154

Gerlach SA, Riemann F (1973) The Bremerhaven checklist of aquatic nematodes. A catalogue of Nematoda Adenophorea excluding the Dorylaimida. Part 1. Veröff Inst Meeresforsch Bremerh, Suppl. 4, Heft 1:1-404

Gerlach SA, Schrage M (1971) Life cycles in marine meiobenthos. Experiments at various temperatures with Monhystera disjuncta and Theristus pertenuis (Nematoda). Mar Biol 9:274-280

Hablutzel PI, Volckaert FAM, Hellemans B, Raeymaekers JAM (2013) Differential modes of MHC class IIB gene evolution in cichlid fishes. Immunogenetics 65:795-809

Hebert PDN, Cywinska A, Ball SL, deWaard JR (2003a) Biological identifications through DNA barcodes. Proc R Soc Lond B Biol Sci 270:313-321

Hebert PDN, Ratnasingham S, deWaard JR (2003b) Barcoding animal life: cytochrome $\mathrm{c}$ oxidase subunit 1 divergences among closely related species. Proc R Soc Lond B Biol Sci 270(Suppl 1):S96-S99

Herman PMJ, Vranken G (1988) Studies of the life history and energetics of marine and brackish-water nematodes II. Production, respiration and food uptake by Monhystera disjuncta. Oecologia (Berlin) 77:457-463

Herman PMJ, Vranken G, Heip C (1984) Problems in meiofauna energy-flow studies. Hydrobiologia 118:21-28

Holterman M, van der Wurff A, van den Elsen S, van Megen $H$, Bongers T, Holovachov O, Bakker J, Helder J (2006) Phylumwide analysis of SSU rDNA reveals deep phylogenetic relationships among nematodes and accelerated evolution toward crown clades. Mol Biol Evol 23:1792-1800

Hopper BE (1969) Marine nematodes of Canada. II. Marine nematodes from the Minas Basin-Scots Bay area of the Bay of Fundy, Nova Scotia. Can J Zool 47:671-690

Jacobs LJ (1987) A checklist of the Monhysteridae (Nematoda, Monhysterida). Rand Afrikaans University, Johannesburg

Kito K (1982) Phytal marine nematode assemblage of Sargassum confusum Agardth, with reference to the structure and seasonal fluctuations. J Fac Sci Hokkaido Univ Ser VI Zool 23(1):143-161

Kreis H (1963) Marine Nematoda. Zool Icel 2(14):1-68

Leduc D (2014) Free-living nematodes of the genus Halomonhystera (Monhysteridae) from the Southwest Pacific region and Ross Sea. N Z J Zool 41(6):46-57

Lein AY, Pimenov NV, Savvichev AS, Vogt P, Bogdanov YA, Sagalevitch AM, Ivanov MV (2000) Methane as a source of organic matter and the hydrocarbon acid of carbonates at a cold seep in the Norwegian Sea. Geohymiya 3:268-281 [in Russian] 
Lorenzen S (1969) Freilebende Meeresnematoden aus dem Schlickwatt und den Sallzwiesen der Nordseeküste. Veröff Inst Meeresforsch Bremerh 9:195-238

Meldal BH, Debenham NJ, De Ley P, De Ley IT, Vanfleteren JR, Vierstraete AR, Bert W, Borgonie G, Moens T, Tyler PA, Austen MC, Blaxter ML, Rogers AD, Lambshead PJ (2007) An improved molecular phylogeny of the Nematoda with special emphasis on marine taxa. Mol Phyl Evol 42:622-636

Mickevich MF, Farris J (1981) The implications of congruence in Menidia. Syst Zool 30:351-370

Mokievsky VO, Filippova KA, Chesunov AV (2005) Nematode fauna associated with detached kelp accumulations in the subtidal zone of the White Sea. Oceanology 45(5):689-697

Nylander JAA (2004) MrModeltest v2. Program distributed by the author. Evolutionary Biology Centre, Uppsala University

Paramonov AA (1929) Svobodnye nematody Kinburnskoi Kosy i sopredel'nykh vod (Free-living nematodes of the Kinburnskaya spit and surrounding waters; Die freilebenden Nematoden der Kinburngense und der angrenzenden Gewässer (Arbeiten der Staatlichen Ichthyologischen Versuchs Station). Trudy Gosud Ikhtiol Opyt St Kherson 4(1):59-129 (in Russian)

Pereira TJ, Fonseca G, Mundo-Ocampo M, Guilherme BC, RochaOlivares A (2010) Diversity of free-living marine nematodes (Enoplida) from Baja California assessed by integrative taxonomy. Mar Biol 157:1665-1678

Poinar G, Duarte D, Santos MJ (2010) Halomonhystera parasitica $\mathrm{n}$. sp. (Nematoda: Monhysteridae), a parasite of Talorchestia brito (Crustacea: Talitridae) in Portugal. Syst Parasitol 75:53-58

Portnova D, Mokievsky V, Soltwedel Th (2011) Nematode species distribution patterns at the Håkon Mosby Mud Vulcano (Norwegian Sea). Mar Ecol 32(1):24-41

Posada D, Buckley TR (2004) Model selection and model averaging in phylogenetics: advantages of akaike information criterion and bayesian approaches over likelihood ratio tests. Syst Biol 53:793-808

Posada D, Crandall KA (1998) MODELTEST: testing the model of DNA substitution. Bioinformatics 14:817-818

Puillandre N, Modica MV, Zhang Y, Sirovich L, Boisselier MC, Cruaud C, Holford M, Samadi S (2012) Large-scale species delimitation method for hyperdiverse groups. Mol Ecol 21:2671-2691

Riemann F (1968) Nematoden aus dem Strandanwurf. Veröff Inst Meeresforsch Bremerh 11:25-35

Riemann F (1995) The deep-sea nematode Thalassomonhystera bathislandica sp. nov. and microhabitats of nematodes in flocculent surface sediments. J Mar Biol Ass UK 75:715-724

Ronquist F, Teslenko M, van der Mark P, Ayres DL, Darling A, Hohna S, Larget B, Liu L, Suchard MA, Huelsenbeck JP (2012) MrBayes 3.2: efficient Bayesian phylogenetic inference and model choice across a large model Space. Syst Biol 61:539-542

Soltwedel Th, Portnova D, Kolar I, Mokievsky V, Schewe I (2005) The small-sized benthic biota of the Håkon Mosby Mud Vulcano (SW Barents Sea slope). J Mar Syst 55:271-290

Steiner G (1916) Freilebende Nematoden aus der Barentssee. Zool Jahrb (Abt. f. Syst., Geogr. Biol. Tiere) 39:511-676

Steiner G (1958) Monhystera cameroni $\mathrm{n}$. sp.-a nematode commensal of various crustaceans of the Magdalen Islands and Bay of Chaleur (Gulf of St. Lawrence). Can J Zool 36:269-278

Swofford DL (1998) PAUP*. Phylogenetic analysis using parsimony (*and other methods). Version 4. Sinauer Associates, Sunderland

Tamura K, Nei M (1993) Estimation of the number of nucleotide substitutions in the control region of mitochondrial DNA in humans and chimpanzees. Mol Biol Evol 10:512-526

Tamura K, Peterson D, Peterson N, Stecher G, Nei M, Kumar S (2011) MEGA5: molecular evolutionary genetics analysis using maximum likelihood, evolutionary distance, and maximum parsimony methods. Mol Biol Evol 28:2731-2739

Tavaré S. (1986) Some probabilistic and statistical problems in the analysis of DNA sequences. In: American Mathematical Society: Lectures on mathematics in the life sciences, vol 17, pp 57-86

Tchesunov AV, Portnova DA (2005) [Free-living nematodes in seasonal coastal ice of the White Sea. Description of Hieminema obliquorum gen. et sp. n. (Nematoda, Monhysteroidea)]. Zoologicheskii Zhurnal 84(8):899-914 (in Russian, English summary)

Tchesunov AV, Riemann F (1995) Arctic sea ice nematodes (Monhysteroidea), with descriptions of Cryonema crassum gen. n., sp. n. and C. tenue sp. n. Nematologica 41:35-50

Thompson JD, Gibson TJ, Plewniak F, Jeanmougin F, Higgins DG (1997) The CLUSTAL_X windows interface: flexible strategies for multiple sequence alignment aided by quality analysis tools. Nucleic Acids Res 25:4876-4882

Trotter D, Webster JM (1983) Distribution and abundance of marine nematodes on the kelp Macrocystis integrifolia. Mar Biol 78:39-43

Tsalolikhin SJ (2007) A review of the genus Geomonhystera (Nematoda, Monhysterida, Monhysteridae) with a description of the new species, G. taurica. Zool Zhurn 86(11):1283-1289 (in Russian, English summary)

Tzetlin AB, Mokievsky VO, Melnikov AN, Saphonov MV, Simdyanov TG, Ivanov IE (1997) Fauna associated with detached kelp in different types of subtidal habitats of the White Sea. Hydrobiologia 355:91-100

Van Campenhout J, Derycke S, Tchesunov AV, Portnova D, Vanreusel A (2014) The dominant Håkon Mosby mud volcano nematode is genetically differentiated from its shallow-water relatives and shows genetic structure within the mud volcano. J Zool Syst Evol Res 52:203-216. doi:10.1111/jzs.12054

Van de Velde M-C, Coomans A (1987) Ultrastructure of the excretory system of the marine nematode Monhystera disjuncta. Tissue Cell 19(5):713-725

Van de Velde M-C, Coomans A (1989) Ultrastructure of the anterior intestine in monhysterids (Nematoda). Ann Soc R Zool Belg 119(2):109-119

Van de Velde M-C, Coomans A (1991) The ultrastructure of the buccal cavity of the monhysterid nematodes Geomonhystera disjuncta and Diplolaimella dievengatensis. Reve Némat 14(1):133-146

Van de Velde M-C, Coomans A (1992) The ultrastructure of the anterior sensory anatomy of the marine monhysterid nematode Geomonhystera disjuncta. Fund appl Nemat 15(3):209-221

Van Gaever S, Moodley L, de Beer D, Vanreusel A (2006) Meiobenthos at the Håkon Mosby mud volcano, with a parental-caring nematode thriving in sulphide-rich sediments. Mar Ecol Prog Ser 321:143-155

Vranken G, Heip C (1986) The productivity of marine nematodes. Ophelia 26:429-442

Vranken G, van Brussel D, Vanderhaeghen R, Heip C (1984) Research on the development of a standardized ecotoxicological test on marine nematodes I. Culturing conditions and criteria for two monhysterids, Monhystera disjuncta and Monhystera microphthalma. In: Persoone G, Jaspers E, Claus C (eds) Ecotoxicological testing for the marine environment, vol 2. State Univ Ghent \& Inst Mar Scient Res, pp 159-184

Vranken G, Vanderhaeghen R, Heip C (1985) Toxicity of cadmium to free-living marine and brackish water nematodes (Monhystera microphthalma, Monhystera disjuncta, Pellioditis marina). Dis Aquat Org 1:49-58

Vranken G, Herman PMJ, Heip C (1988) Studies of the life-history and energetics of marine and brackish-water nematodes $\mathrm{I}$. 
Demography of Monhystera disjuncta at different temperature and feeding conditions. Oecol (Berl) 77:296-301

Vranken G, Tiré C, Heip C (1989) Effect of temperature and food on hexavalent chromium toxicity to the marine nematode Monhystera disjuncta. Mar Environ Res 27:127-136

Wieser W (1956) Freeliving marine nematodes III. Axonolaimoidea and Monhysteroidea. Acta Univ lund (N. F. 2) 52(13):1-115
Will KW, Mishler BD, Wheeler QD (2005) The perils of DNA barcoding and the need for integrative taxonomy. Syst Biol $54: 844-851$

Zekely J, Sørensen MV, Bright M (2006) Three nematode species (Monysteridae) from deep-sea hydrothermal vents. Meiofauna Mar 15:25-42 